\title{
COMPOSIÇÃO E EVOLUÇÃO DOS FLUIDOS NO DEPÓSITO AURÍFERO SÃO FRANCISCO, FAIXA SERIDŌ, PROVÍNCIA BORBOREMA, NORDESTE DO BRASIL
}

\author{
WANILSON LUIZ-SILVA ${ }^{1}$, JEAN MICHEL LEGRAND ${ }^{1} \&$ ROBERTO PEREZ XAVIER ${ }^{2}$
}

\begin{abstract}
COMPOSITION AND EVOLUTION OF FLUIDS IN THE SÃO FRANCISCO GOLD DEPOSIT, SERIDO BELT, BORBOREMA PROVINCE, NORTHEAST BRAZIL The São Francisco gold deposit is located within the Seridó Belt, Borborema Province, Northeast Brazil. The deposit area consists predominantly of mica schists and minor calc-silicate lenses (Seridó Formation), that are metamorphosed to mid-upper amphibolite facies conditions and cut by pegmatite intrusions. The primary mineralization is considered to have occurred synchronously with the peak metamorphism and is hosted by the sillimanite-muscovite zone confined to a sin- $S$, medium to high angle shear zone, all considered to be Neoproterozoic. Free gold, or associated with $\mathrm{Fe} \pm \mathrm{Cu} \pm \mathrm{Pb}$ sulfides (especially pyrite), occurs within the veins or host mica schists as interstitial fine grains (primary mineralization) or segmented in millimeter- to centimeter-sized fractures (secondary mineralization). This study, accomplished in auriferous and barren quartz veins, consisted of the investigation in the mode of occurrence of the fluid inclusion populations, their textural relationships and analyses by microthermometry and Raman microspectroscopy. Four types of fluid inclusions have been identified, in decreasing order of abundance: type $1-\mathrm{CO}_{2}$, with subordinate amounts of $\mathrm{CH}_{4}$ and $\mathrm{N}_{2}$; type $2-\mathrm{H}_{2} \mathrm{O}$, could contain a complex mixture of solutes; type $3-\mathrm{CH}_{4}$-rich; and type $4-\mathrm{H}_{2} \mathrm{O}-\mathrm{CO}_{2}$, with low-salinity. Most of the fluid inclusion populations occur along inter- and intragranular healed microfractures. Types 1,3 and 4 are texturally the earliest and fill low- to moderate-angle microfractures, whereas type 2 inclusions are later and delineate mostly moderate- to high-angle microfractures, all referred to the XZ surface of finite strain ellipsoid. The microfractures host only one fluid inclusion type, except in one barren vein where carbonic (type 1) and aqueous-carbonic (type 4) inclusions were found along the same microfracture. In general, the auriferous veins contain fluid inclusions of types 1,2 and 3 , whereas the barren veins show types 1 and 2 or 1,2 and 4 . Dissolved salts in the aqueous fluid inclusions (type 2) of the barren veins are dominated by $\mathrm{NaCl}$ $( \pm \mathrm{KCl})$, but in the auriferous veins $\mathrm{NaCl}, \mathrm{CaCl}$ and probably $\mathrm{KCl}, \mathrm{LiCl}, \mathrm{MgCl}$ and $\mathrm{FeCl}$, appear as important solutes. The results of this study, combined with structural, petrographic and metamorphic data, demonstrate that the circulation of aqueous-carbonic (low salinity) and aqueous fluids (varied salinity) occurred coevally during peak metamorphism and formation of the São Francisco gold deposit. Most of the inclusions of the aqueous-carbonic fluids suffered dehydration post-entrapment (the current carbonic inclusions) and the variable salinity of the aqueous fluids is consequence of the chemical mobility during the metamorphism. The primary mineralizing fluids were probably low-salinity aqueouscarbonic and both chlorine- (possibly dominant) and sulfur-complexes may have had an important role in the transport of the gold. It is possible that aqueous fluids with complex salts played a prominent role in the remobilization of the primary gold (sulfides) to the fractures. Although further studies are necessary for a better assessment of the processes responsible in the deposition of the primary gold, mixing of fluids, sulfidation and immiscibility within the fluid conduits (veins) appear to have been particularly important.
\end{abstract}

Keywords: Fluid Inclusions, Microthermometry, Raman Spectroscopy, Economic Geology, Seridó Belt.

RESUMO O depósito aurífero São Francisco, situado na Faixa Seridó, Nordeste do Brasil, é constituído por micaxistos com lentes de rocha cálcio-silicática (Formação Seridó), que estão metamorfizados em condições da fácies anfibolito médio-superior e cortados por intrusões de pegmatito A mineralização primária é contemporânea ao pico do metanorfismo, está alojada na zona da silimanita-muscovita e ocorre associada com veios de quartzo confinados $\mathrm{em}$ uma zona de cisalhamento $\sin -\mathrm{S}_{3}$ (mergulho de médio-alto ângulo), todos referidos ao neoproterozóico. $\mathrm{O}$ ouro, livre ou associado com sulfetos de $\mathrm{Fe} \pm \mathrm{Cu} \pm \mathrm{Pb}$ (especialmente pirita), ocorre dentro dos veios ou encaixantes, como grãos finos intersticiais (mineralização primária) ou segmentados em fraturas milimétricas a centimétricas (mineralização secundária). Este estudo, realizado $\mathrm{em}$ veios de quartzo auríferos e estéreis, consistiu na investigação do modo de ocorrência das populações de inclusões fluidas, suas relações texturais e análises por microtermometria e microespectroscopia Raman. Foram identificados quatro tipos de inclusões fluidas, por ordem decrescente de abundância: tipo 1 - $\mathrm{CO}_{2}$, com concentraçôes subordinadas de $\mathrm{CH}_{4}$ e $\mathrm{N}_{2}$; tipo $2-\mathrm{H}_{2} \mathrm{O}$, podendo conter uma mistupor ordem decrescente de abundância: tipo $1-\mathrm{CO}_{2}$, com concentraçoes subordinadas de $\mathrm{CH}_{4}$ e $\mathrm{N}_{2}$; tho $2-\mathrm{H}_{2} \mathrm{O}$, podendo de solutos; tipo 3 - ricas em $\mathrm{CH}_{4}$; e tipo $4-\mathrm{H}_{2} \mathrm{O}-\mathrm{CO}_{2}$, com baixa salinidade. A maioriá das populaçes de fluidas ocorre em microfraturas cicatrizadas inter e intragranulares. Os tipos $1,3 \mathrm{e} 4$, texturalmente os mais antigos, estão relacionados a microfraturas de baixo-médio ângulo, com relação à superfície XZ do elipsóide de deformação finita, ao passo que o tipo 2 é posterior e encontra-se especialmente em microfraturas de médio-alto ângulo. As microfraturas hospedam apenas um tipo de inclusões fluidas, com exceção de um veio estéril que apresenta inclusões carbônicas (tipo 1) e aquo-carbônicas (tipo 4) em uma mesma microfratura. Em geral, os veios auríferos apresentam téril que apresenta inclusões carbônicas (tipo 1) e aquo-carbônicas (tipo 4) em uma mesma microfratura. Em geral, os veios auríferos apresentam
inclusões fluidas tipos $1,2 \mathrm{e} 3$, enquanto os veios estéreis mostram os tipos 1 e 2 ou $1,2 \mathrm{e} 4$. Os sais dissolvidos nas inclusões aquosas (tipo 2) dos veios estéreis são dominados por $\mathrm{NaCl}( \pm \mathrm{KCl})$, mas nos veios auríferos $\mathrm{NaCl}, \mathrm{CaCl}$ e provavelmente $\mathrm{KCl}, \mathrm{LiCl}, \mathrm{MgCl}_{2}$ e FeCl devem ser solutos importantes. Os resultados deste estudo, combinados com dados estruturais, petrográficos e metamórficos, denunciam que fluidos aquo-carbônicos (baixa salinidade) e aquosos (salinidade variada) circularam durante o pico do metamorfismo e formação do depósito aurífero São Francisco. A maioria das inclusões dos fluidos aquo-carbônicos sofreu desidratação pós-aprisionamento (atuais inclusões carbônicas) e a variável salinidade dos fluidos aquosos é conseqüência da mobilidade química durante o metamorfismo. Os fluidos mineralizantes primários foram provavelmente aquo-carbônicos com baixa salinidade e o ouro pode ter sido transportado tanto na forma de complexos clorados (possivelmente dominantes), quanto na forma de complexos de enxofre. É possível que fluidos aquosos com sais complexos tenham sido importantes na remobilização do ouro (sulfetos) primário para as fraturas. Embora sejam necessários estudos adicionais para um melhor entendimento dos processos responsáveis pela deposição do ouro primário, mistura de fluidos, sulfetação e imiscibilidade de fases dentro dos condutos de fluidos (veios) devem ter exercido um papel importante.

Palavras-chave: Inclusões Fluidas, Microtermometria, Espectroscopia Raman, Geologia Econômica, Faixa Seridó.

INTRODUÇÃO O estudo de inclusões fluidas em minerais tem se consolidado como uma ferramenta importante na obtenção de informações sobre a composição e evolução dos fluidos em sistemas metamórfico-hidrotermais, magmático-hidrotermais ou meteóricohidrotermais e depósitos minerais associados, e auxiliado na definição da trajetória de pressão e temperatura (e.g. Hollister 1990, Sisson \& Hollister 1990, Craw \& Norris 1993, Xavier et al. 1994, Johnson \& Hollister 1995, Olsen \& Ferry 1995, Xavier \& Foster 1999). Um dos grandes desafios do estudo de depósitos auríferos, em particular os do tipo veio (lode-gold deposits) confinados em zonas de cisalhamento, tem sido elucidar os fatores que promoveram as condições de formação das mineralizações em locais preferenciais ao longo das estruturas hospedeiras. Em algumas áreas, estes fatores podem estar ligados à ge- ometria estrutural (e.g. Robert et al. 1990, Groves 1990, Sibson 1990 , Sibson \& Scott 1998), às características dos fluidos circulantes (e.g. Robert \& Kelly 1987) ou a uma combinação de condições físicas e/ou químicas particulares (e.g. Romberger 1990, Kerrich \& Cassidy 1994). Contudo, é indiscutível que os fluidos exercem um importante papel no transporte do ouro, cuja deposição está relacionada às mudanças nas variáveis físico-químicas do sistema hidrotermal (cf. Mikucki 1998, McCuaig \& Kerrich 1998). Considerando estes aspectos, o estudo de inclusões fluidas constitui uma importante ferramenta para o discernimento dos fatores que causaram a formação de mineralizações.

$O$ estudo aqui apresentado investiga as inclusões fluidas em amostras de veios de quartzo mineralizados e estéreis do depósito aurífero São Francisco, Nordeste do Brasil, com o objetivo de avaliar a nature-

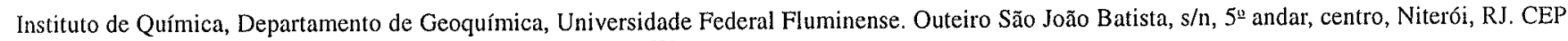
24020-007. E-mails: wanilsonls@bol.com.br, legrand@geoq.uff.br

2 Instituto de Geociências, Departamento de Metalogênese e Geoquímica, Universidade Estadual de Campinas. Caixa Postal 6152, Campinas, SP. CEP 13083970. E-mail: xavier@ige.unicamp.br 
za dos fluidos que circularam no ambiente tectono-metamórfico. A combinação deste estudo com investigações estruturais, petrográficas e metamórficas permite discutir a evolução dos fluidos e sua relação com a formação da mineralização.

AMBIENTE GEOLóGico A área de estudo contém o depósito aurífero São Francisco (DASF) e está localizada na Província Borborema (Almeida et al. 1977), no domínio da Faixa Seridó, Nordeste do Brasil (Fig. 1). A geologia regional tem sido documentada em vários trabalhos (e.g. Jardim de Sá 1984, Hackspacher et al. 1997, Luiz-Silva et al. 1997), sendo apresentado a seguir um resumo da mesma.

O embasamento da região é constituído por gnaisses e migmatitos, com idades arqueana e paleoproterozóica (Dantas et al. 1995). Sobre este contexto repousa discordantemente uma sequiência de rochas supracrustais de idade neoproterozóica (Van Schmus et al. 1996), pertencentes ao Grupo Seridó. De acordo com Jardim de Sá \& Salim (1980), a unidade basal deste grupo é a Formação Jucurutu, constituída por gnaisses, anfibolitos, mármores e rochas cálcio-silicáticas. A unidade intermediária é a Formação Equador, representada por quartzitos e metaconglomerados, e a superior, Formação Seridó, constituída por micaxistos e filitos. Durante a Orogênese Brasiliana, o embasamento e a sequeencia de rochas supracrustais foram intrudidos por batólitos (stocks, soleiras, diques) graníticos a granodioríticos, subordinadamente gabróicos a tonalíticos. A região sofreu uma complexa evolução tectônica durante o Neoproterozóico, marcada por estruturas de baixo e alto ângulos (e.g. foliações $\mathrm{S}_{2}$ e $\mathrm{S}_{3}$, respectivamente), sobre as quais ocorreram cavalgamentos $\left(\mathrm{S}_{2}\right)^{3} \mathrm{e}$ cisalhamentos transcorrentes $\left(\mathrm{S}_{3}\right)$. Neste contexto, as condições metamórficas foram da fácies xisto-verde até anfibolito superior, salientando-se que alguns setores sofreram metamorfismo de contato (localmente fácies granulito) ou anatexia.

A área do DASF situa-se no topo estratigráfico do Grupo Seridó (Formação Seridó) e é composta por uma sequêencia de micaxistos feldspáticos, com abundância de minerais índices aluminosos, e com os quais se associam níveis ou lentes centimétricas a decimétricas de rocha cálcio-silicática e corpos métricos de pegmatito (Fig. 2).

A estruturação do DASF tem sido interpretada como resultante de deformação progressiva, marcada especialmente pela inflexão gradual do mergulho da foliação, de $15^{\circ}$ para $80^{\circ} \mathrm{SE}$ (cf. Luiz-Silva et al. 1997). Esta inflexão ocorreu segundo um eixo NNE e caracteriza a evolução de $S_{2}$ (baixo ângulo) para $S_{3}$ (alto ângulo). Não há um limite claro quanto ao final de $\mathrm{S}_{2}$ e início se $\mathrm{S}_{3}$, entretanto, Luiz-Silva et al.
(1997) propuseram um limite teórico que seria no mergulho ao redor de $35^{\circ}$, em virtude das características do rake da lineação de estiramento mineral. Na foliação com mergulho inferior a $35^{\circ}\left(\mathrm{S}_{2}\right)$, esta lineação normalmente ostenta rake $>45^{\circ}$, ao passo que na foliação com mergulho superior a $35^{\circ}\left(\mathrm{S}_{3}\right)$ a lineação apresenta rake $<30^{\circ}$ (geralmente subhorizontal). As estruturas de alto ângulo apresentam mergulhos predominantemente entre $45^{\circ}$ e $80^{\circ} \mathrm{SE}$, e aqueles superiores a $55^{\circ} \mathrm{SE}$ caracterizam os setores mais deformados, que definem as zonas de cisalhamento transcorrente.

O metamorfismo na área do DASF tem sido interpretado como regional e hidrotermal. O regional está relacionado às transformações minerais, durante as quais a circulação de fluidos não foi significativa. A cristalização mineral esteve condicionada à deformação (Luiz-Silva 1995). Os micaxistos representativos são constituídos especialmente por biotita $(\mathrm{Fe} / \mathrm{Mg} \sim 1)+$ quartzo + plagioclásio $\left(\mathrm{X}_{\mathrm{an}} \sim 0,23\right.$ a 0,30$)+$ granada $\left(X_{1, m} \sim 0,7\right)$ e caracterizam a zona da granada (Fig. 2).

A infiltraçã̃o de fluidos nos micaxistos da zona da granada resultou na cristalização significativa de minerais índices aluminosos, especialmente cordierita, estaurolita, andaluzita, muscovita e silimanita, caracterizando o metamorfismo hidrotermal, documentado ao longo de toda Formação Seridó (e.g. Legrand \& França 1989, França \& Legrand 1989. Cunha de Souza et al. 1991, Legrand et al. 1992, 1995, LuizSilva 1995, Luiz-Silva et al. 1993, 1994, Cunha de Souza 1996). Cálculos de balanço de massa indicam que a geração destes minerais ocorreu em meio à mobilidade expressiva de alguns componentes químicos (e.g. $\mathrm{Si}, \mathrm{Ca}, \mathrm{Na}, \mathrm{K}, \mathrm{H}_{2} \mathrm{O}$ ) e imobilidade ou baixa mobilidade de outros (e.g. Al, Ti, Fe, Mn, Mg; Legrand et al. 1992, Cunha de Souza 1996, Luiz-Silva et al. 2000, Luiz-Silva em prep.). A participação do magmatismo brasiliano neste episódio, como fonte termal e de fluidos, tem sido admitida como de grande importância. O desenvolvimento de zonas de cisalhamento, aliado à característica físsil dos micaxistos, teve um papel fundamental para a mobilização de fluidos em escala regional. O metamorfismo hidrotermal foi responsável, na área do DASF, pela geração das zonas da cordierita-andaluzita (localmente ocorre estaurolita) e silimanita-muscovita (Fig. 2). A primeira zona representa o início do hidrotermalismo, enquanto a zona da silimanitamuscovita, o ápice.

Dados geotermobarométricos, com base na química mineral, revelam que as zonas metamórficas da área investigada foram submetidas a semelhantes condições de $\mathrm{P}(3,5 \pm 0,7 \mathrm{kbar})$ e $\mathrm{T}\left(574^{\circ} \pm 30^{\circ} \mathrm{C}\right)$, e a cristalização de diferentes minerais índices aluminosos foi controlada particularmente pela atividade de elementos químicos na fase fluida (Luiz-Silva \& Legrand 1996).

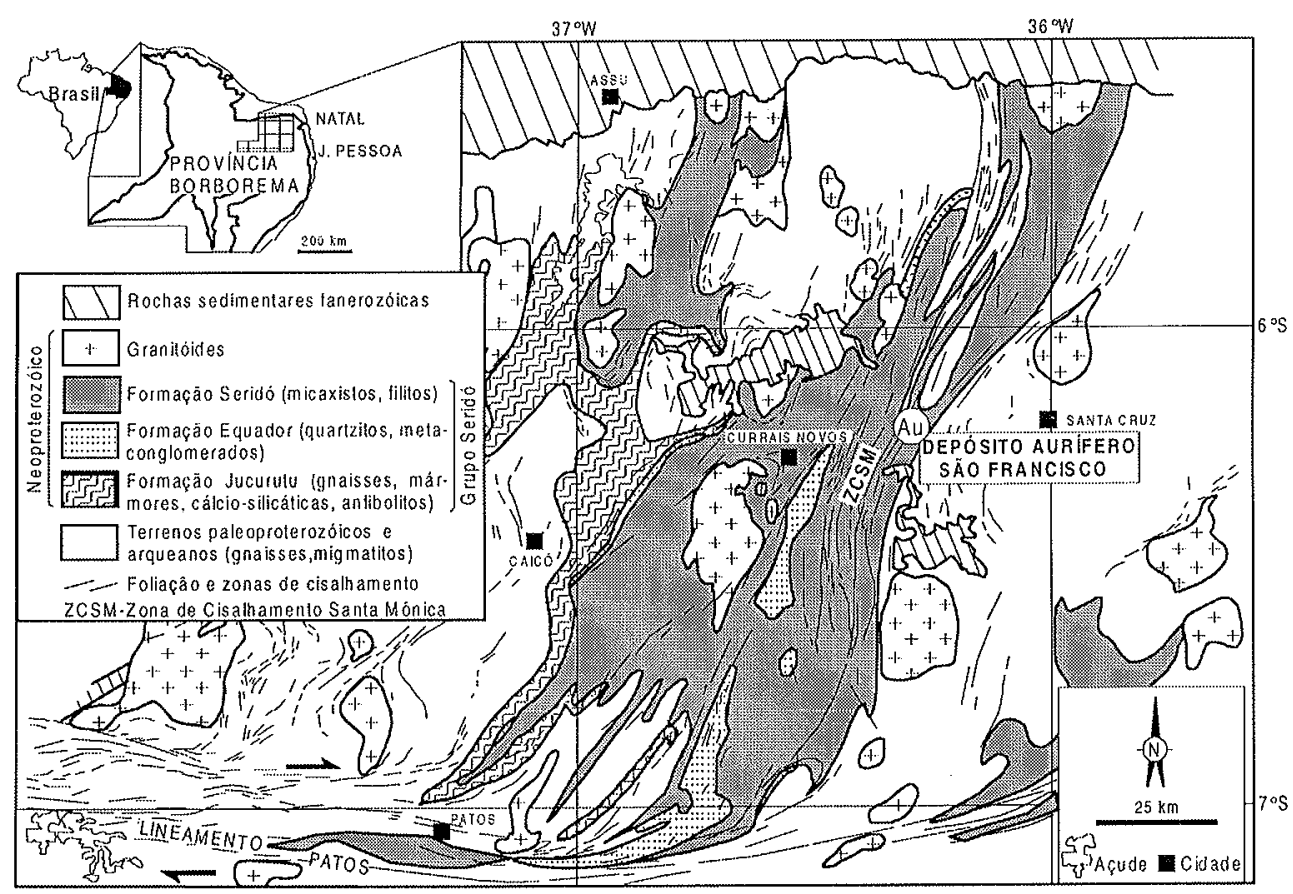


PRINCIPAIS ASPECTOS DA MINERALIZAÇ̃O AURÍFERA Os aspectos da mineralização do DASF estão detalhados em Luiz-Silva (1995), sendo resumidas a seguir as principais características com algumas informações apresentadas em Luiz-Silva (em prep.). O minério está encaixado em granada-silimanita-muscovita-biotita xistos feldspáticos (zona da silimanita-muscovita), normalmente bastante deformados. O evento mineralizante primário é interpretado como sinmetamórfico, em condições da fácies anfibolito, e sin- $\mathrm{S}_{3}$.

A faixa mineralizada (Fig. 2) está inserida na zona de cisalhamento São Francisco, denominação local (Luiz-Silva 1995) de um dos segmentos do cisalhamento regional Santa Mônica (Fig. 1). As reservas totais do minério alcançaram em 1987, 4 toneladas de ouro contido, com um teor médio de 2,5 a $6,6 \mathrm{ppm}$, localmente $100 \mathrm{ppm}$ (Ferran 1988).

A mineralização pode ser dividida em primária (estágios 1 e 2) e secundária. Ocorre também uma faixa supergênica, normalmente intemperizada (capeamento superficial irregular do trend mineralizado, com 1 a $5 \mathrm{~m}$ de espessura), marcada pela alteração de sulfetos (goetitização/limonitização de pirita é comum) e não é considerada nesta síntese.

Mineralização primária O estágio 1 da mineralização primária é caracterizado pela presença de ouro livre ou associado com pequena quantidade de pirita, pirrotita e ocasionalmente calcopirita. Esta forma de ocorrência está associada com setores dos micaxistos encaixantes normalmente bastante deformados. O ouro pode ser visível a olho nu e geralmente constitui grãos finos, mas foram observados exemplares ligeiramente esféricos ou irregulares com 1 a $4 \mathrm{~mm}$ (dimensão mais longa). O ouro livre ou associado com sulfetos ocorre de forma intersticial no interior de veios de quartzo, na interface destes com os micaxistos encaixantes, ou em meio à foliação destas rochas. Quando relacionado com os veios de quartzo, o ouro constitui grãos geralmente subesféricos, ao passo que nos micaxistos constitui escamas acomodadas no plano de foliação $S_{3}$ (delgadas placas, com $<1$ a $3 \mathrm{~mm}$ de dimensão mais longa, paralelas à $S_{3}$ ). As escamas podem ser constituídas essencialmente de ouro ou conter pequena quantidade de pirita (pirrotita, calcopirita).

Os veios relacionados com o estágio 1 geralmente são pouco espessos $(<10 \mathrm{~cm})$, sendo aqueles com espessura inferior a $2 \mathrm{~cm}$ bastante freqüentes. Muitas vezes o ouro disseminado na foliação dos micaxistos encaixantes está associado com vênulas quartzosas, mas em várias situações este metal ocorre livre na foliação, sem conotação com mobilizados silicosos.

O estágio 2 da mineralização primária é representado por veios de quartzo com agregados intersticiais de sulfetos. Ao contrário do estágio anterior, o estágio 2 é caracterizado pelo conteúdo significativo de sulfetos, dominados por pirita, seguindo-se galena (localmente abundante), calcopirita e pirrotita. A molibdenita ocorre raramente associada com galena. Os sulfetos também ocorrem em níveis milimétricos a submilimétricos confinados na foliação $S_{3}$ dos micaxistos encaixantes. O ouro é difícil de ser observado em amostras do estágio 2 , mas as análises geoquímicas de rocha total revelam sua presença (Luiz-Silva em prep.). Pelo menos um grão de ouro muito fino foi observado ao microscópio, na forma de inclusão em pirita intemperizada. Os veios sulfetados apresentam normalmente espessura entre 10 e $15 \mathrm{~cm}$, mas podem formar bolsões com até $25 \mathrm{~cm}$ de espessura.

RELACÃO ENTRE OS ESTÁGIOS 1 E 2 O estágio 1 está ligado aos setores estruturais geralmente bastante deformados, os quais apresentam a foliação $S_{3}$ proeminente, e é o mais rico em ouro. O estágio 2 ocorre de forma intermitente em meio ao estágio 1 e está associado com setores normalmente menos deformados, sendo possível identificar foliações pré-S $S_{3}$ A presença marcante de pirita (galena, calcopirita, pirrotita) no estágio 2 , aliada à diminuição da concentração do ouro, revela uma característica importante do minério do DASF: quanto maior a concentração de sulfetos, menor o conteúdo aurífero.

Mineralização secundária A mineralização secundária é caracterizada pela concentração do ouro \pm sulfetos (especialmente pirita) em fraturas, com tamanho milimétrico (ocasionalmente centimétrico), geralmente oblíquas à direção de $\mathrm{S}_{3}$. As fraturas ocorrem tanto nos veios da mineralização primária, quanto nos micaxistos encaixantes $\mathrm{e}$

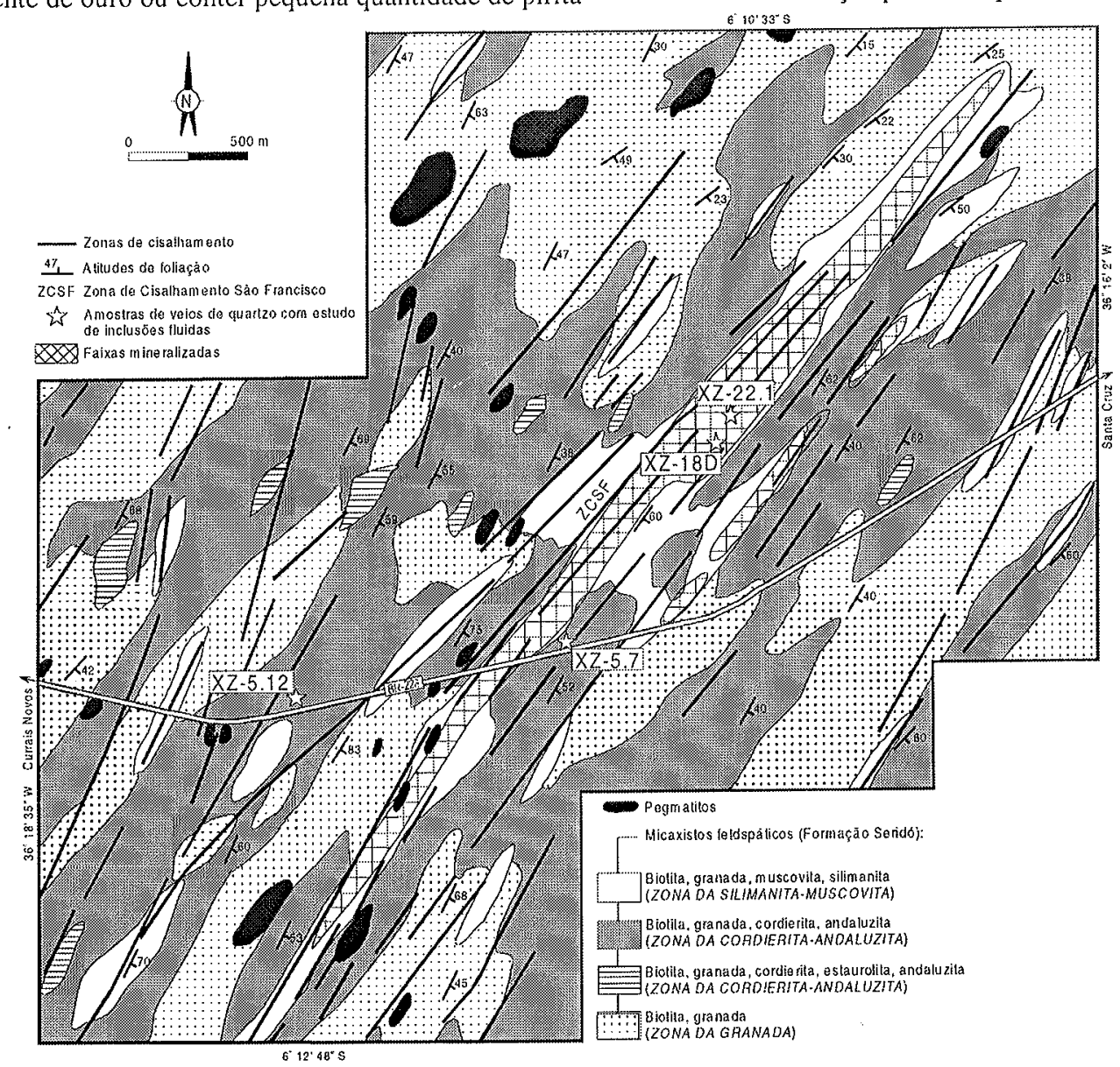

Figura 2 - Mapa metamórfico-estrutural simplificado da área do depósito aurífero São Francisco, com a localização das amostras investigadas (Modificado de Luiz-Silva 1995). 


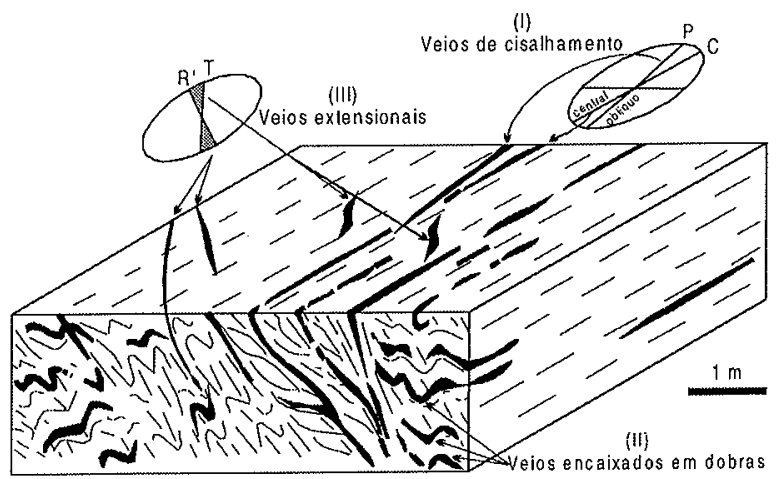

Figura 3 - Representação esquemática dos tipos geométricos de veios que ocorrem na área investigada: tipo (I) - veios de cisalhamento central (C) $e$ oblíquo (P); tipo (II) - veios encaixados em dobras; e tipo (III) - veios extensionais.

o ouro foi observado como grãos segmentados, livres ou associados com pirita. Esta forma de mineralização é interpretada como conseqüência de remobilização do ouro e sulfetos primários.

\section{NATUREZA DOS VEIOS E AS AMOSTRAS SELECIONADAS PARA O ESTUDO DE INCLUSÖES FLUI- \\ DAS Os veios da área do DASF situam-se especialmente no contex-} to das zonas de cisalhamento com mergulho em alto ângulo ( $\sin -\mathrm{S}_{3}$ ), podem ser essencialmente quartzosos ou conter pequena quantidade de plagioclásio, biotita, sillimanita, muscovita e turmalina. Apresentam espessura geralmente inferior a $20 \mathrm{~cm}$ e, quanto à geometria, são classificados nos seguintes tipos (Fig. 3): (I) veios paralelos a levemente oblíquos com relação à direção de $\mathrm{S}_{3}$ - veios de cisalhamento; (II) veios que acompanham pequenas estruturas dobradas; e (III) veios extensionais.

Os veios tipo I constituem os principais hospedeiros da mineralização aurífera e correspondem aos veios de cisalhamento central (tipo $\mathrm{C}$, paralelos à $\mathrm{S}_{3}$ ) e oblíquo (tipo $\mathrm{P}$ ), respectivamente, de acordo com a classificação de Hodgson (1989). Foram gerados simultaneamente, sendo o oblíquo posicionado de $5^{\circ}$ a $15^{\circ}$ sinistrogiro à direção de $S_{3}$. São contínuos por dezenas de metros ou descontínuos (boudins), estão associados com faixas mais deformadas e ocorrem como enxames ou isoladamente.

Os veios tipo II são tão freqüentes quanto os tipo I e ocasionalmente constituem corpos mineralizados. Quando observados segundo cortes subhorizontais nos afloramentos, os veios tipo II mostram-se concordantes com a direção de $S_{3}$ e confundem-se com os tipo I. A distinção é feita nos cortes verticais, em virtude da forma dobrada dos veios tipo II (dobras desenhadas por $S_{1}$ ou $S_{2}$ ). Admite-se que estes veios não foram necessariamente dobrados, mas injetados em uma foliação dobrada, ou em curso de dobramento (Luiz-Silva et al. 1997). Sua geração é interpretada como consequiência da fuga de $\mathrm{SiO}_{2}$ das zonas de alta pressão (cisalhamentos) para sítios de alívio de pressão, durante a formação de $\mathrm{S}_{3}$. Os veios tipo II ocorrem em faixas com poucos metros de espessura, ladeadas por zonas com intensa deformação.

Os veios tipo III posicionam-se em ângulos superiores a $37^{\circ} \mathrm{com}$ relação à direção de $\mathrm{S}_{3}$, são estéreis e os menos numerosos. Ocorrem segundo fraturas 'T e R', (raramente $\mathrm{R}$ ) em segmentos retilíneos ou em forma de "S", com extensão inferior a $1 \mathrm{~m}$.

As inclusões fluidas foram analisadas em quatro seções polidas nas duas faces, cortadas paralelas ao plano XZ do elipsóide de deformação finita e assim distribuídas: (1) duas amostras de veios de quartzo auríferos tipo I (amostras XZ-22.1 e XZ-18D; mineralização primária, estágios indistintos); (2) uma amostra de veio de quartzo estéril tipo I (amostra XZ-5.12); e (3) uma amostra de veio de quartzo estéril tipo III (amostra XZ-5.7). Os veios auríferos ocorrem no interior da zona da silimanita-muscovita, ao passo que os estéreis, particularmente os investigados, na zona da cordierita-andaluzita, salientando-se que veios estéreis também ocorrem nas zonas da silimanita-muscovita e granada (Luiz-Silva em prep.).

Nas amostras dos veios tipo I (auríferos e estéreis), os grãos de quartzo exibem microestruturas tais como lamelas de deformação e formação de subgrãos e grãos, indicando a ação da deformação dúctil, posterior à geração dos veios. Estas feições são incipientes na amostra do veio tipo III, na qual predominam grandes cristais de quartzo com extinção ondulante. Em adição a estas microestruturas, ocorrem microfraturas que não necessariamente denunciam ambiente rúptil, lembrando que a alta pressão de fluidos pode agir como atenuante da pressão litostática, proporcionando condições frágeis mesmo em ambiente dúctil (e.g. Etheridge et al. 1984).

\section{MODO DE OCORRÉNCIA E TIPOS DE INCLUSÓES FLUI-}

DAS As amostras investigadas dos veios auríferos, além de quartzo, contêm pirita e calcopirita, ao passo que as dos estéreis contêm essencialmente quartzo. A maioria das inclusões fluidas examinadas localiza-se em microfraturas cicatrizadas que podem ser classificadas, com relação à superfície $\mathrm{XZ}$ do elipsóide de deformação finita, nos seguintes estilos: (a) microfraturas de baixo-médio ângulo (ocasionalmente subhorizontais); c (b) microfraturas de médio-alto ângulo (ocasionalmente subverticais). As microfraturas normalmente cruzam limites de grãos (intergranulares), podendo eventualmente se restringirem a um grão (intragranulares). A observação de casos de truncamento de microfraturas de baixo-médio ângulo por outras de médio-alto ângulo sugere que estas últimas são mais jovens. Com base nos critérios de Roedder (1984), a maioria das inclusões estudadas pode ser interpretada como secundária e pseudo-secundária (e.g. inclusões alojadas em microfraturas inter e intragranulares, respectivamente). Em poucos casos, inclusões primárias foram investigadas, ocorrendo isoladas ou agrupadas em arranjos desordenados no interior e nos limites de grãos de quartzo.

Com relação à composição, as inclusões observadas podem ser classificadas em quatro tipos: carbônicas (tipo 1), aquosas (tipo 2), ricas em $\mathrm{CH}_{4}$ (tipo 3) e aquo-carbônicas (tipo 4), em ordem decrescente de abundância. As microfraturas de baixo-médio ângulo estão relacionadas normalmente às inclusões tipos 1,3 e 4 , ao passo que as microfraturas de médio-alto ângulo estão preenchidas pelas inclusões tipo 2. Os agrupamentos primários (menos freqüentes) geralmente são compostos pelos tipos 1 ou 2 e não foram evidenciados agrupamentos compostos pelos dois tipos. Nos veios auríferos foram encontradas inclusões fluidas tipos 1, 2 e 3 , ao passo que nos veios estéreis os tipos 1 e 2, e, excepcionalmente no veio extensional, o tipo 4. Embora mais de um tipo de inclusões fluidas tenha sido encontrado em uma mesma amostra, as microfraturas são constituídas por apenas um tipo, exceto o veio extensional que pode acomodar, em uma mesma microfratura, inclusões carbônicas e aquo-carbônicas.

$\mathrm{O}$ tamanho das inclusões fluidas investigadas pode chegar a $30 \mu \mathrm{m}$ (dimensão mais longa), mas a maioria apresenta menos de $12 \mu \mathrm{m}$. São predominantemente irregulares, podendo exibir formas de cristal negativo e tubo (Fig. 4). Em temperatura ambiente $\left(\sim 20^{\circ} \mathrm{C}\right)$, as inclusões carbônicas apresentam uma ou duas fases (líquido e vapor; Figs. 4a-b); $\mathrm{e}$ as aquosas podem conter de uma a três fases (líquido, vapor e cristal de halita; Figs. 4c-e).

As inclusões ricas em $\mathrm{CH}_{4}$ e as aquo-carbônicas não ocorrem com freqüência. Em temperatura ambiente, as inclusões ricas em $\mathrm{CH}_{4}$ são monofásicas (vapor) e as aquo-carbônicas apresentam três ou, ocasionalmente, duas fases: $\mathrm{H}_{2} \mathrm{O}$ líquido $+\mathrm{CO}_{2}$ líquido $+\mathrm{CO}_{2}$ vapor ou $\mathrm{H}_{2} \mathrm{O}$ líquido $+\mathrm{CO}$ líquido. A razão $\mathrm{H}_{2} \mathrm{O}: \mathrm{CO}_{2}$ nas inclusões aquocarbônicas oscifa muito, com a fração aquosa constituindo normalmente de $30 \%$ do volume até uma película entre a fase carbônica e as paredes da inclusão. Entretanto, em algumas situações, $\mathrm{o} \mathrm{H}_{2} \mathrm{O}$ pode ocupar atê $90 \%$ do volume da inclusão. Algumas inclusões fluidas associadas às microfraturas que alojam inclusões carbônicas ou ricas $\mathrm{em} \mathrm{CH}_{4}$ parecem ter sido crepitadas naturalmente (inclusões pretas, Fig. 4b).

MICROTERMOMETRIA Os dados de microtermometria foram obtidos em uma platina LINKAM THMSG600, do Laboratório de Microanálise do Instituto de Geociências e Ciências Exatas da Universidade Estadual Paulista. A calibração do instrumento foi realizada com substâncias químicas com pontos de fusão conhecidos: inclusões naturais de $\mathrm{CO}$ puro $\left(\sim-56,6^{\circ} \mathrm{C}\right)$, água deionizada $\left(\sim 0^{\circ} \mathrm{C}\right), \mathrm{KNO}_{3}(\sim$ $\left.335^{\circ} \mathrm{C}\right)$ e $\mathrm{K}_{2} \mathrm{Cr}_{2} \mathrm{O}_{7}\left(\sim 398^{\circ} \mathrm{C}\right)$. As temperaturas de fusão final do $\mathrm{CO}_{2}$ congelado ( $\mathrm{Tf}_{\mathrm{CO}}$ ) e do gelo ( $\mathrm{Tf}_{\mathrm{rclo}}$ ), e da primeira fusão do gelo (temperatura do eutetico - $\mathrm{T}$ ) foram medidas usando uma taxa de aquecimento de $1^{\circ}$ a $2^{\circ} \mathrm{C} /$ minuuto. As temperaturas de homogeneização total do $\mathrm{CH}_{4}\left(\mathrm{Th}_{\mathrm{CH} 4}\right), \mathrm{CO}_{2}\left(\mathrm{Th}_{\mathrm{CO}}\right)$ e da fusão final de clatratos foram obtidas mediante uma taxa de aquecimento de $2^{\circ}$ a $5^{\circ} \mathrm{C} /$ minuto. A reprodução das medidas situou-se geralmente entre $\pm 0,2^{\circ} \mathrm{C}$. A obtenção da temperatura de homogeneização total de inclusões aquosas ( $\mathrm{Th}_{\mathrm{H} 2 \mathrm{O}}$ ) ocorreu com uma taxa de aquecimento da ordem de $5^{\circ}$ a $10^{\circ} \mathrm{C} /$ minuto, com reprodução dos resultados entre $\pm 2^{\circ} \mathrm{C}$. 
Inclusões carbônicas (tipo 1) VEIOS AURÍFEROS Em 56 inclusões carbônicas investigadas, a $\mathrm{Tf}_{\mathrm{co}}$ ocorre no intervalo de $62,2^{\circ}$ a $-56,6^{\circ} \mathrm{C}$, com maior concentração de valores em torno de $60,5^{\circ} \mathrm{Ce}-56,6^{\circ} \mathrm{C}$ (Fig. 5a).

A Th ${ }_{\text {coj }}$ em 92 inclusões carbônicas analisadas ocorre no intervalo de $12^{\circ}$ a $38^{\circ} \mathrm{C}$, invariavelmente para o estado líquido, com maior freqüência nos intervalos de $14^{\circ}$ a $15^{\circ} \mathrm{C}, 19^{\circ}$ a $20^{\circ} \mathrm{C}, 23^{\circ}$ a $24^{\circ} \mathrm{C}$ e $28^{\circ}$ a $29^{\circ} \mathrm{C}$ (Fig. 6a).

VEIOS ESTÉREIS Nos veios estéreis, a $\mathrm{Tf}_{\text {CO }}$ das inclusões carbônicas apresenta-se sob dois aspectos: (a) 56 inclusões estudadas no veio tipo I mostram $\mathrm{Tf}_{\mathrm{CO} 2}$ no intervalo de $-60,9^{\circ}$ a $-56,6^{\circ} \mathrm{C}$, semelhante aos veios auríferos, com maior concentração de valores em torno de $-60,5^{\circ}$ e $-57,5^{\circ} \mathrm{C}$ (Fig. 5b); e (b) o veio tipo III, com 175 inclusões carbônicas investigadas, apresenta $\mathrm{Tf}_{\mathrm{CO} 2}$ entre $-59,8^{\circ}$ e $-56,6^{\circ} \mathrm{C}$,
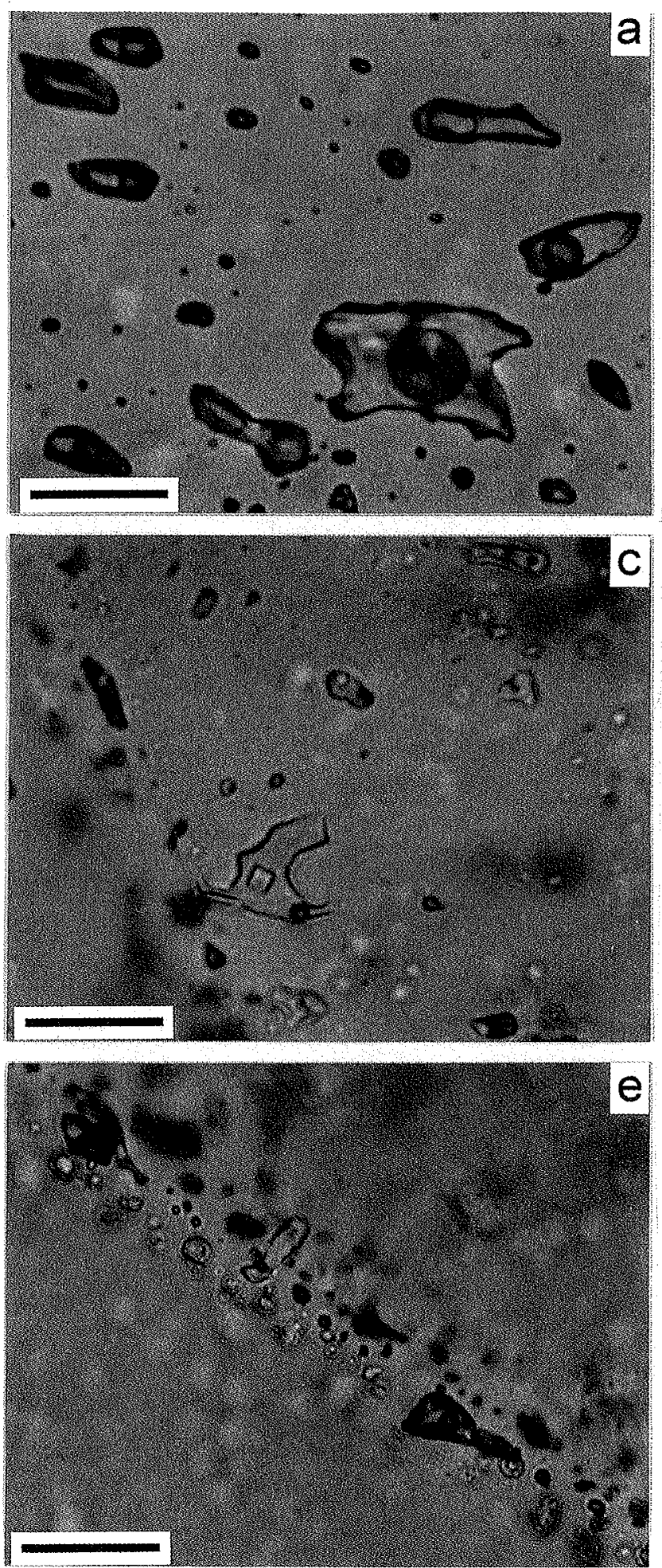

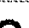

com uma alta concentração de valores no intervalo de $-57,0^{\circ}$ a $-56,6^{\circ}$ C (Fig. 5c).

A Th ${ }_{\mathrm{CO} 2}$ foi obtida de 45 e 182 inclusões carbônicas nos veios estéreis tipo $\mathrm{T}$ e tipo III, respectivamente, e sempre ocorreu para o estado líquido. No veio tipo I, os valores distribuem-se entre $10^{\circ}$ e $26^{\circ} \mathrm{C}$, com maior concentração entre $15^{\circ} \mathrm{e} 19^{\circ} \mathrm{C}$ (Fig. 6b). No veio tipo III, a $\mathrm{Th}_{\mathrm{CO} 2}$ ocorre no intervalo de $16^{\circ}$ a $30^{\circ} \mathrm{C}$ (Fig. 6c), salientando-se que a concentração de valores aumenta à medida que se aproxima de $29^{\circ} \mathrm{C}$.

Inclusões aquosas (tipo 2) As inclusões aquosas investigadas foram especialmente as que continham, em temperatura ambiente, fase aquosa líquida + vapor de $\mathrm{H}_{2} \mathrm{O}$ ou fase aquosa líquida + vapor de $\mathrm{H}_{2} \mathrm{O}$ + cristal de halita. A homogeneização total destas inclusões ocorreu para o estado líquido.
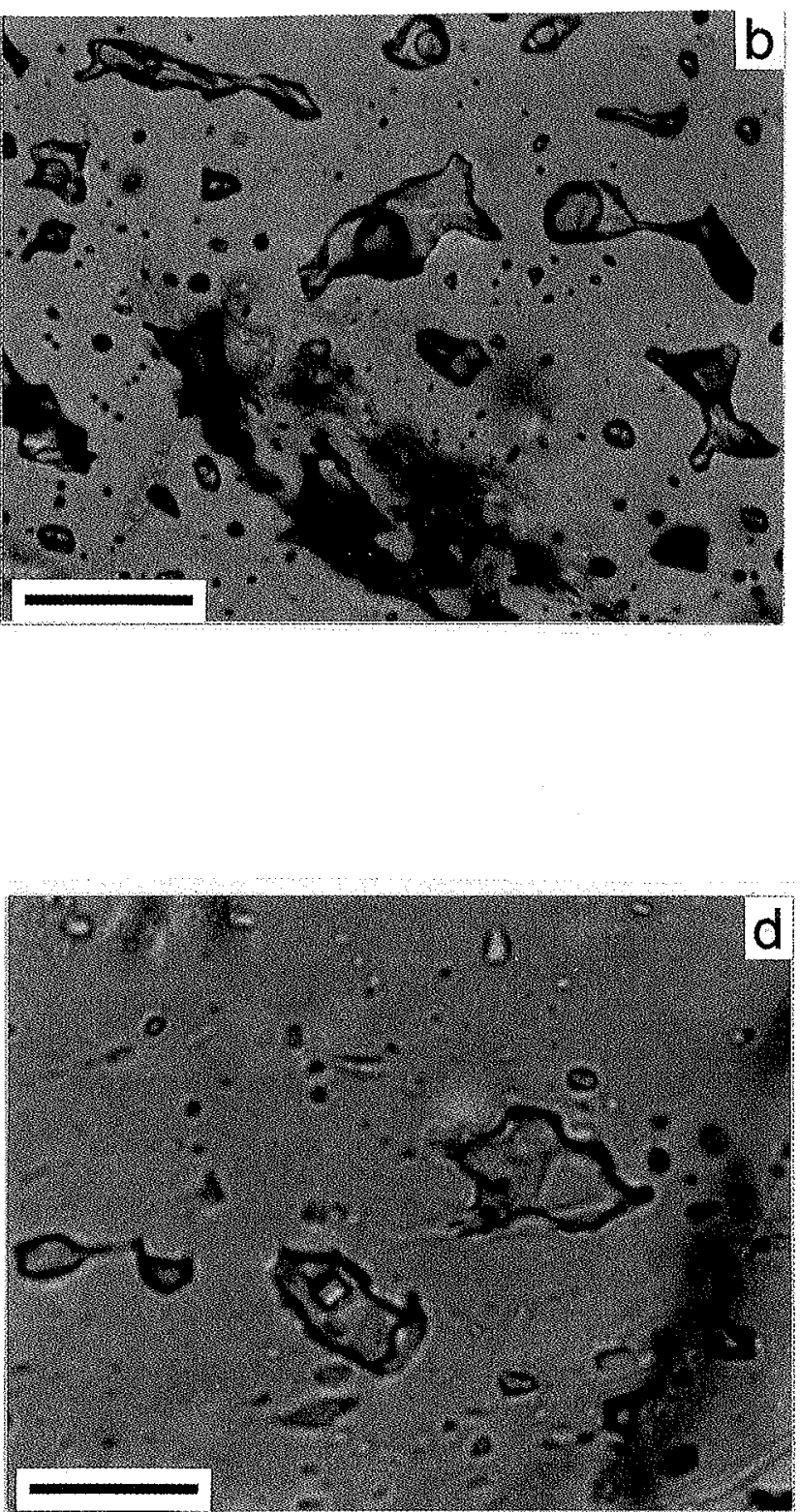

Figura 4 - Inclusões fluidas carbônicas (tipo 1) e aquosas (tipo 2) representativas dos veios de quartzo auríferos e estéreis da área do depósito aurífero São Francisco: (a) e (b) mostram os aspectos das inclusões carbônicas; (c) (d) e (e) exibem a forma e as fases presentes nas inclusões aquosas, com cristais de halita em (c) $e(d)$. Luz transmitida. A barra de referência $=20 \mu m$. 
VEIOS AURÍFEROS Os valores obtidos para a Tf 35 inclusões aquosas investigadas, podem ser divididos em três grupos (Fig. 7a): o primeiro concentra-se entre $-57,5^{\circ}$ e $-52,5^{\circ} \mathrm{C}$; o segundo compreende o intervalo de $-40^{\circ}$ a $-20^{\circ} \mathrm{C}$; e o terceiro, $-12,5^{\circ}$ a $0^{\circ} \mathrm{C}$. Os valores mais baixos de $\mathrm{Tf}_{\text {gclo }}$ não necessariamente se correlacionam às inclusões aquosas com cristal de halita.

A temperatura da primeira fusão do gelo foi determinada em $-76,5^{\circ}$, $-75^{\circ}$ (três medidas) e $\sim-52^{\circ} \mathrm{C}$, e correspondem às inclusões aquosas

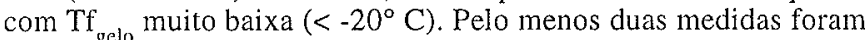
obtidas gelo inclusão com cristal de halita. As inclusões com Tf entre $-12,5^{\circ}$ e $0^{\circ} \mathrm{C}$ apresentam $\mathrm{T}$ próxima a $-20^{\circ} \mathrm{C}$ (cinco medidas).

Os valores de $\mathrm{Th}_{\text {uro }}$, de um total de 42 inclusões aquosas, distribuem-se entre $75,5^{\circ}$ e $390,3^{\circ} \mathrm{C}$, com maior concentração de valores entre $100^{\circ}$ e $190^{\circ} \mathrm{C}$ (Fig. 8a).

VEIOS ESTÉREIS As inclusões aquosas dos veios de quartzo estéreis apresentam valores de $\mathrm{Tf}$ distribuídos da seguinte forma: (a) no veio tipo I, intervalos de $-30^{\circ}$ a $-22,5^{\circ} \mathrm{C},-15^{\circ}$ a $-12,5^{\circ} \mathrm{Ce}-7,5^{\circ}$ a $0^{\circ}$ $\mathrm{C}$ (Fig. 7b); e (b) no veio tipo III, intervalos de $-25^{\circ}$ a $-20^{\circ} \mathrm{Ce}-12,5^{\circ}$ a $0^{\circ} \mathrm{C}$ (Fig. 7c). As inclusões com $\mathrm{Tf}_{\text {clo }}>-15^{\circ} \mathrm{C}$ representam $\sim 85 \%$ das medidas no veio tipo I (21 inclusoes analisadas) $\mathrm{e} \sim 95 \%$ no veio tipo III (31 inclusões analisadas).

A temperatura do eutético foi determinada em $-43,8^{\circ},-50^{\circ}$ e $-53^{\circ} \mathrm{C}$, correspondente às inclusões com Tf $\mathrm{f}_{\mathrm{relo}}<-20^{\circ} \mathrm{C}$. As inclusões com $\mathrm{Tf}<-15^{\circ} \mathrm{C}$ apresentam $\mathrm{T}$ em torno de $-20^{\circ} \mathrm{C}$ (quatro medidas). Os valores de $\mathrm{Th}_{\mathrm{H} 20}$ das inclusões aquosas dos veios estéreis tipo I (40 inclusões) e tipo III ( 52 inclusões) ocorrem nos intervalos de $77,5^{\circ}$ a $460^{\circ} \mathrm{C}$ e $100^{\circ}$ a $350,4^{\circ} \mathrm{C}$, respectivamente. Em ambas as amostras, a maior concentração de valores de $\mathrm{Th}_{\mathrm{H} 2 \mathrm{O}}$ ocorre abaixo de $190^{\circ} \mathrm{C}$ (Figs. 8b-c).

Inclusões ricas em $\mathbf{C H}_{4}$ (tipo 3) Apenas uma das amostras dos veios auríferos (XZ-18D) apresenta este tipo de inclusões, no qual a única mudança de fase identificada foi a homogeneização total, para o estado vapor, das fases líquida + vapor, que ocorre entre $-90^{\circ} \mathrm{e}-$ $83,2^{\circ} \mathrm{C}$ (Fig. 9).

Inclusões aquo-carbônicas (tipo 4) Estas inclusões foram encontradas excepcionalmente na amostra do veio estéril tipo III e obtenção dos dados microtermométricos foi limitada, devido à escassez e ao pequeno tamanho destas inclusões (raramente maiores que 7 $\mu \mathrm{m})$.

Foram investigadas 15 inclusões aquo-carbônicas que apresentam os seguintes resultados: (a) $\mathrm{Tf}_{\mathrm{cos}}$ entre $-56,8^{\circ}$ e $-56,6^{\circ} \mathrm{C}$; (b) fusão inicial do gelo estimada $\mathrm{em}-19^{\circ} \mathrm{C}$; (c) temperatura de fusão final de clatratos entre $7,4^{\circ}$ e $8,5^{\circ} \mathrm{C}$; (d) $\mathrm{Th}_{\mathrm{Cos}}$ entre $21,7^{\circ}$ e $26,8^{\circ} \mathrm{C}$, invariavelmente para o estado vapor; e (e) temperatura de homogeneização total (raramente obtida devido à crepitação antes) em $423^{\circ} \mathrm{C}$ (para o estado vapor) e entre $287^{\circ}$ e $316,6^{\circ} \mathrm{C}$ (para o estado líquido).

MICROESPECTROSCOPIA RAMAN Análises qualitativas e quantitativas de inclusões individuais carbônicas (tipo 1) e ricas em $\mathrm{CH}_{4}$ (tipo 3) foram realizadas por microespectroscopia Raman, utilizando-se uma microssonda Raman a laser, modelo T64000 da Jobin Ivon, com microscópio petrográfico convencional acoplado, no Laboratório de Inclusões Fluidas do Instituto de Geociências da Universidade Estadual de Campinas. A radiação empregada foi a da linha 514,5 nm (linha verde) de um laser de argônio, com uma potência de 600 $\mathrm{mW}$ na fonte e tempo de integração de 300 segundos para a análise de cada espécie volátil na inclusão. Discussões detalhadas sobre este método analítico podem ser encontradas em Xavier (1987) e Kerkhof (1988). Todos os dados aqui apresentados sobre inclusões carbônicas foram obtidos de populações com $\mathrm{Tf}_{\mathrm{CO}}>-58^{\circ} \mathrm{C}$.

Veios auríferos Foram analisadas 3 inclusões carbônicas e resultados indicam: (a) $\mathrm{CO}$ puro em dois casos; e (b) composição de 97,1 mol\% de $\mathrm{CO}_{2}+2,4$ mol\% de $\mathrm{CH}_{4}+0,5$ mol\% de $\mathrm{N}_{2}$ em um caso. Análises em duas inclusões com a temperatura de homogeneização total em $-90,7^{\circ} \mathrm{e}-83,2^{\circ} \mathrm{C}$ indicam $\mathrm{CH}_{4}$ puro (inclusões tipo 3 ).

Veios estéreis No veio tipo I, duas análises em inclusões carbônicas indicam $\mathrm{CO}_{2}$ puro e uma indica composição de 97,3 mol\% de $\mathrm{CO}_{2}+0,3 \mathrm{~mol} \% \mathrm{de}^{2} \mathrm{CH}_{4}+2,4 \mathrm{~mol} \%$ de $\mathrm{N}_{2}$. No veio tipo III, quatro inclusões carbônicas apresentam as seguintes composições: (a) $95,9 \mathrm{~mol} \% \mathrm{CO}_{2}+0,1 \mathrm{~mol} \% \mathrm{CH}_{4}+4 \mathrm{~mol} \% \mathrm{~N}_{2}$; (b) $91,2 \mathrm{~mol} \% \mathrm{CO}_{2}+$ $0,2 \mathrm{~mol} \% \mathrm{CH}_{4}+8,6 \mathrm{~mol} \% \mathrm{de} \mathrm{N}_{2}$; (c) $98,2 \mathrm{~mol}^{2} \% \mathrm{CO}_{2}+1,8 \mathrm{~mol} \% \mathrm{~N}_{2}$; e (d) $96,9 \mathrm{~mol} \% \mathrm{CO}_{2}+3,1 \mathrm{~mol}_{2} \mathrm{~N}_{2}$.
DISCUSSÃO Características das inclusões fluidas dos veios auríferos e estéreis Os dados de microtermometria e/ou microespectroscopia Raman mostram que há uma variação expressiva na composição das inclusões fluidas dos veios de quartzo da área do DASF, com alguns aspectos particulares entre os veios auríferos e estéreis.

A temperatura do cutético próxima a $-20^{\circ} \mathrm{C}$, representativa de muitas inclusões aquosas (com Tf entre $-15^{\circ}$ e $0^{\circ} \mathrm{C}$ ) dos veios auríferos e estéreis, denuncia una composição química compatível com o sistema $\mathrm{H}_{2} \mathrm{O}-\mathrm{NaCl}$ (sistema com $\mathrm{T}$ entre $-20,8^{\circ}$ e $-21,2^{\circ} \mathrm{C}$ ). Entretanto, a $\mathrm{T}$ no intervalo de $-43,8^{\circ}$ a $-76,5^{\circ} \mathrm{C}$ e Tf ${ }^{\circ}<-20^{\circ} \mathrm{C}$, obtidas de um número significativo de inclusões aquosas, especialmente nos veios auriferos, e algumas delas com cristal de halita, indcam a presença de fluidos de composição química mais complexa, possivelmente com Na, K, Ca, Li, Mg, Fe e Cl (cf. Roedder 1984, Robert \& Kelly 1987, Sherlock et al. 1993). T tão baixa quanto -76 $\mathrm{C}$ pode denunciar a presença de $\mathrm{LiCl}$ (e.g. Robert \& Kelly 1987). Entretanto, alguns estudos mostram que $\mathrm{T}$ desta magnitude também pode ser encontrada no sistema $\mathrm{H}_{2} \mathrm{O}-\mathrm{CaCl}_{2}-\mathrm{NaCl}$, que normalmente apresenta $\mathrm{T}$ entre $-52^{\circ}$ e $-55^{\circ} \mathrm{C}$, devido à fusão metaestável de compostos de cálcío hidratados, como por exemplo CaCl $.4 \mathrm{H}_{2} \mathrm{O}$ (cf. Davis et al. 1990, Molnár et al. 1999). Além da fusão metáestável, a variação nos valores de $\mathrm{T}_{\mathrm{c}}$, particularmente nas inclusões investigadas com $\mathrm{Tf}_{\mathrm{uclo}}<$ $-20^{\circ} \mathrm{C}$, pode ser devido, também, às limitações visuais do observador (Sherlock et al. 1993). Quando um maior volume de fusão é formado próximo ao eutético, a mudança de fase é vista mais facilmente e a temperatura registrada estará próxima ao eutético verdadeiro. Entretanto, quando apenas um pequeno volume de fusão é formado próximo ao eutético, a mudança de fase pode permanecer imperceptível até que um volume maior de fusão seja formado, bem abaixo do eutético verdadei10 .

É provável que as inclusões aquosas investigadas devam representar dois sistemas químicos, com sais dissolvidos em várias proporções. $\mathrm{O}$ primeiro é formado por $\mathrm{H}_{2} \mathrm{O}-\mathrm{NaCl}$ e é representado pelas inclusões com Tf $>-15^{\circ} \mathrm{C} \mathrm{e} \mathrm{T} \sim-20^{\circ} \mathrm{C}$. Pode ser admitida ainda neste sistema, a presença do $\mathrm{KCl}$, cuja $\mathrm{T}\left(-22,9^{\circ}\right.$ a $\left.-23,5^{\circ} \mathrm{C}\right)$ estaria muito próxima ao eutético do $\mathrm{H}_{2} \mathrm{O}-\mathrm{NaCl}\left(-20,8^{\circ}\right.$ e $\left.-21,2^{\circ} \mathrm{C}\right)$. O segundo sistema é composto por $\mathrm{H}_{2} \mathrm{O}-\mathrm{CaCl}_{2}-\mathrm{NaCl} \pm \mathrm{KCl} \pm \mathrm{LiCl} \pm \mathrm{MgCl}_{2} \pm \mathrm{FeCl}_{2}$ e é representado pelas inclusões com $\mathrm{Tf}_{\mathrm{fo}}<-20^{\circ} \mathrm{Ce} \mathrm{T}$ entre $-43,8^{\circ} \mathrm{e}$ $76,5^{\circ} \mathrm{C}$. Embora as inclusões deste ûttimo sistema possam apresentar cristais de halita, a complexidade química do fluido inviabiliza a uti-
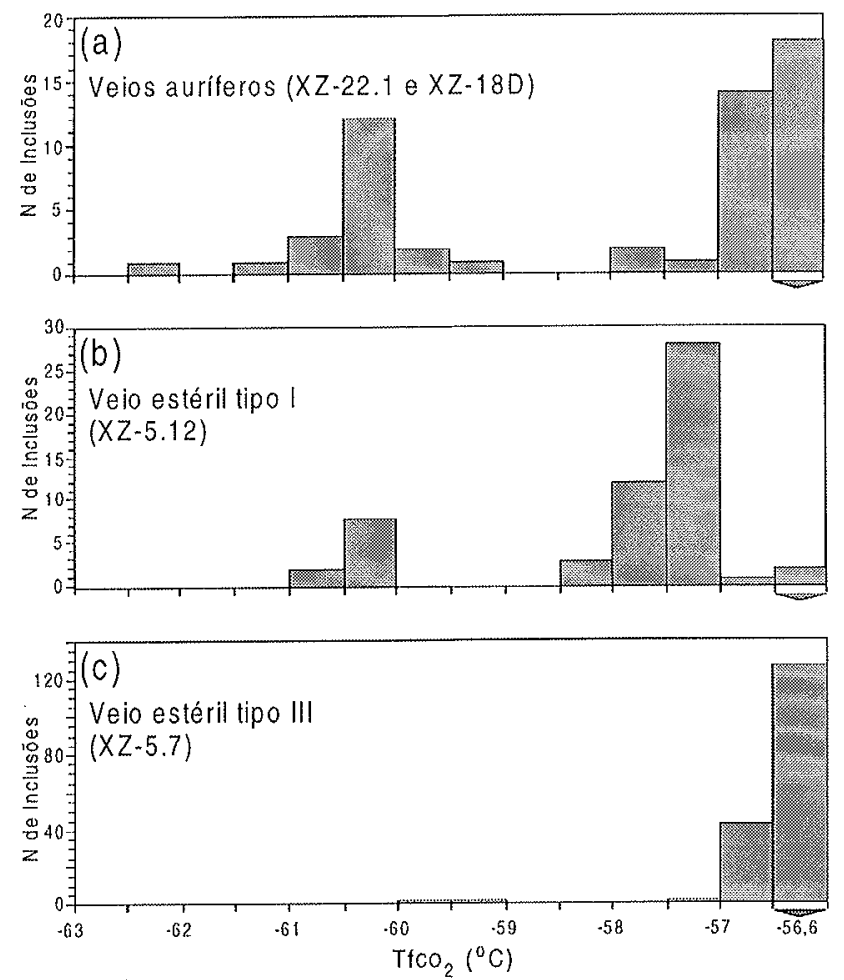

Figura 5 - Histogramas de frequiência de temperaturas de fusão final do $\mathrm{CO}_{2}$ de inclusões carbônicas (Tf $\mathrm{CO}_{2}$ ). 

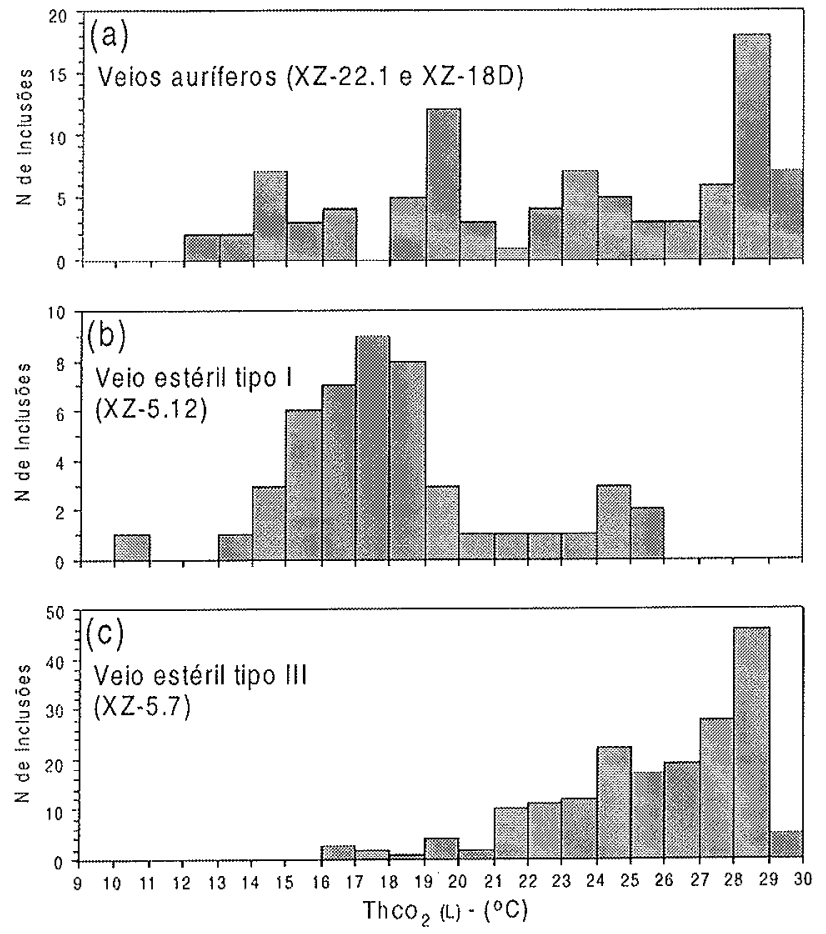

Figura 6 - Histogranas de frequiencia de temperaturas de homogeneização total do $\mathrm{CO}_{2}$, para o estado líquido, de inclusóes carbônicas (Th $\mathrm{CO}_{2}(\mathrm{~L})$ ).

lização da temperatura de dissolução destes cristais para se estimar a salinidade (conteúdo de $\mathrm{NaCl}$ ). Ademais, em um sistema quimicamente complexo, a presença de cristais de halita não necessariamente indica uma solução saturada em $\mathrm{NaCl}$. Por exemplo, uma solução contendo $31 \%$ em peso de $\mathrm{CaCl}_{2}$ e somente $3 \%$ em peso de $\mathrm{NaCl}$ iria precipitar apenas cristais de $\mathrm{NaCl}$ (Fuzikawa 1985). Considerando apenas as inclusões fluidas analisadas compatíveis com o sistema $\mathrm{H}_{2} \mathrm{O}-\mathrm{NaCl}$ (sistemas mais complexos são de difícil modelagem), a densidade das mesmas oscila entre $0,53 \mathrm{e} 1,06 \mathrm{~g} / \mathrm{cm}^{3}$ e a salinidade, entre $\sim 0 \mathrm{e}$ $18,62 \%$ em peso de $\mathrm{NaCl}$.

Em todas as amostras analisadas, as inclusões aquosas apresentam maior concentração de valores de $\mathrm{Th}_{\mathrm{H} 2 \mathrm{O}}$ abaixo de $200^{\circ} \mathrm{C}$ (Fig. 8). Como inclusões com esta característica ocorrem associadas a outras com valores de $\mathrm{Th}_{\mathrm{H}-\mathrm{O}}$ maiores, é provável reequilíbrio pós-aprisionamento do fluido.

Um aspecto particular entre os veios investigados, com referência às inclusões aquosas, é que os estéreis são dominados por inclusões de $\mathrm{H}_{2} \mathrm{O}-\mathrm{NaCl} \pm \mathrm{KCl}$, ao passo que os auríferos, por inclusões de $\mathrm{H}_{2} \mathrm{O}$ $\mathrm{CaCl}_{2}-\mathrm{NaCl} \pm \mathrm{KCl} \pm \mathrm{LiCl} \pm \mathrm{MgCl}_{2} \pm \mathrm{FeCl}_{2}$. Esta diferença deve ser reflexo do hidrotermalismo que atuou nos micaxistos encaixantes dos veios, conforme discutido abaixo.

Os baixos valores de $\mathrm{Tf}_{\mathrm{CO}}$ (Fig. 5) e os dados do Raman indicam que as inclusões carbônicas tendem a apresentar além do $\mathrm{CO}_{2}$, pequena concentração de $\mathrm{CH}_{4}$ e $\mathrm{N}_{2}$, com tendência a uma maior presença de $\mathrm{CH}_{4}$ nos veios auríferos e $\mathrm{N}_{2}$ prevalecendo nos estéreis. A presença de discretas inclusões de $\mathrm{CH}_{4}$ nos veios auríferos também confirma o alto conteúdo deste composto nos corpos mineralizados, relativo aos estéreis. Esta característica é consistente com os estudos realizados por Robert \& Kelly (1987), Shepherd et al. (1991) e Sherlock et al. (1993) que encontraram al to conteúdo de $\mathrm{CH}_{4}$ correlacionado com alta concentração de ouro.

A oscilação na Th ${ }_{\mathrm{CO} 2}$ das inclusões carbônicas é significativa (Fig. 6) e indica tanto a variação da densidade do $\mathrm{CO}_{2}$, quanto a presença de $\mathrm{CH}_{4}$ e/ou N (cf. Kerkhof \& Olsen 1990). Nas inclusões com Tf próxima a $-56,6^{\circ} \mathrm{C}$, e portando constituídas particularmente por $\mathrm{CO}_{2}$, a densidade varia entre 0,60 e $0,86 \mathrm{~g} / \mathrm{cm}^{3}$ e esta variação deve refletir reequilíbrios pós-aprisionamento do fluido.

As inclusões aquo-carbônicas são compostas por $\mathrm{CO}_{2}$ praticamente puro, com densidade do $\mathrm{CO}_{2}$ entre $0,21 \mathrm{e} 0,27 \mathrm{~g} / \mathrm{cm}^{3}$. Esta densidade é muito menor que a das inclusões carbônicas que ocupam a mesma microfratura $\left(0,60\right.$ e $\left.0,86 \mathrm{~g} / \mathrm{cm}^{3}\right)$ e deve refletir reequilíbrio pós-aprisionamento do fluido. A julgar pela temperatura de fusão final de
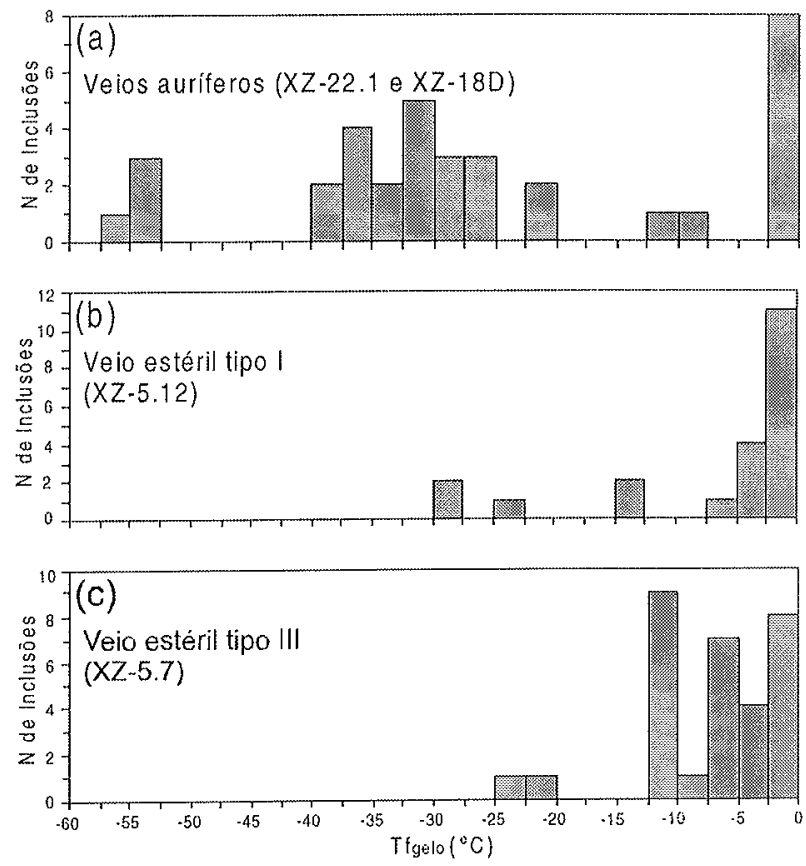

Figura 7 - Histogramas de frequiência de tenperaturas de fusão final do gelo $\left(T f_{\text {geto }}\right)$ de inclusóes aquosas.
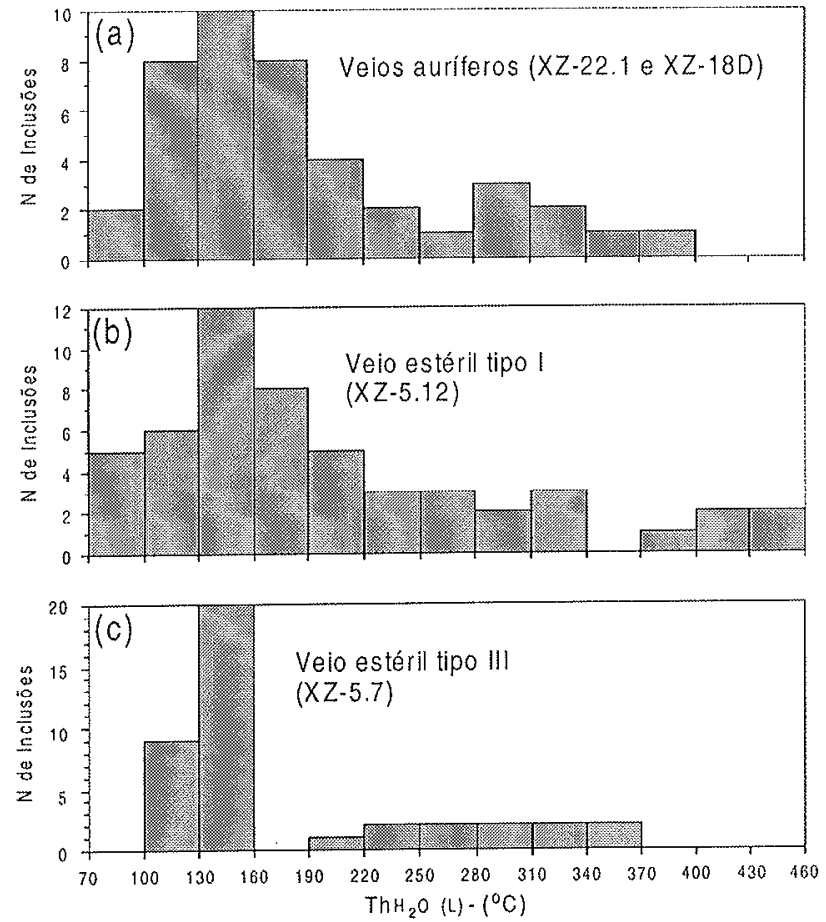

Figura 8 - Histogramas de frequiência de temperaturas de homogeneizalção total, para o estado líquido, de inclusões aquosas $\left(T h_{H 2 O}(L)\right.$ ).

clatratos (entre $7,4^{\circ}$ e $8,5^{\circ} \mathrm{C}$ ), a fração aquosa das inclusões aquocarbônicas deve conter baixa concentração de $\mathrm{NaCl}(\sim 3$ a $5 \%$ em peso de $\mathrm{NaCl}$ - Diamond 1994).

Isócoras versus geotermobarometria A isócora é uma linha no espaço P-T ao longo da qual a densidade do fluido aprisionado (inclusão) permanece constante em um sistema quimicamente fechado. Ela pode representar tanto os reequilíbrios na densidade do fluido aprisionado durante a evolução geológica de uma determinada área, quanto as condições originais de aprisionamento deste fluido. Na área investigada, apenas as inclusões aquosas e carbônicas pertencentes a sistemas quimicamente simples $\left(\mathrm{H}_{2} \mathrm{O}-\mathrm{NaCl}\right.$ e $\left.\mathrm{CO}_{2}\right)$ foram utilizadas 
para o cálculo das isócoras, utilizando-se o programa FLINCOR 1.4 (Brown 1989) e as equações de estado de Brown \& Lamb (1989).

É uma questão delicada obter-se informação sobre as condições P$\mathrm{T}$ de um ambiente tectono-metamórfico a partir da temperatura de homogeneização de inclusões fluidas, especialmente quando há evidências de reequilíbrio (densidade, composição) pós-aprisionamento do fluido. Entretanto, a integração dos dados geotermobarométricos (química mineral) e microtermométricos (inclusões fluidas) pode contribuir para uma melhor compreensäo deste cenário. As condições do pico metamórfico da área do DASF $\left(3,5 \pm 0,7\right.$ kbar e $\left.574^{\circ} \pm 30^{\circ} \mathrm{C}\right)$ foram definidas por Luiz-Silva (1995), mediante controle das paragêneses de minerais metamórficos e equações geotermobarométricas. Conforme exposto acima, as inclusões carbônicas e aquosas estudadas não são texturalmente cogenéticas. Isso pode inviabilizar a definição das condições de P-T com base na confluência das isócoras destes fluidos, uma vez que a contemporaneidade entre as inclusões é um pré-requisito básico para esta aplicação. Contudo, a Figura 10 mostra isócoras de $\mathrm{H}_{2} \mathrm{O}-\mathrm{NaCl}$ (e.g. isócoras e-h) e de $\mathrm{CO}_{2}$ (e.g. isócoras $\mathrm{k}, \mathrm{l}$ ) que cruzam a região do pico metamórfico, sugerindo que ambos os fluidos foram aprisionados ou reequilibrados durante este episódio. Como as relações texturais mostram hierarquia entre as inclusões carbônicas (mais antigas) e aquosas (mais jovens), é provável que uma parcela de ambas tenha sido formada dentro do campo do pico metamórfico, mas separada por um hiato de tempo.

\section{Regimes de fluidos: transporte e deposição do ouro} Com base nas evidências apresentadas neste estudo, integradas aos elementos estruturais, petrográficos e metamórficos da área do DASF, é possível propor a evolução dos fluidos que circularam durante 0 metamorfismo. O pressuposto fundamental baseia-se no fato das inclusões carbônicas serem texturalmente as mais antigas e na evidente presença do $\mathrm{H}_{2} \mathrm{O}$ durante todo o metamorfismo da área do depósito, como sugerem as assembléias de minerais metamórficos (ricas em micas; Luiz-Silva 1995). Assim, sugere-se que inicialmente o regime de fluidos foi aquo-carbônico e posteriormente aquoso. As inclusões aprisionadas dos fluidos aquo-carbônicos (raramente observadas) devem ter sofrido, em sua maioria, desidratação, transformando-se nas atuais inclusões carbônicas.

A presença comum de inclusões carbônicas em veios de ambientes metamórficos e, em muitos casos, a ausência do $\mathrm{H}_{2} \mathrm{O}$, tem sido tema de discussões polêmicas, especialmente quando há evidências de que uma componente aquosa circulava durante o metamorfismo (e.g. Hollister 1990, Xavier 1994, Xavier \& Foster 1999). Algumas investigações teóricas e experimentais vêm tentando esclarecer este enigma (e.g. Watson \& Brenan 1987, Craw \& Norris 1993, Johnson \& Hollister 1995). Os estudos teóricos têm analisado, sobretudo, a formação de inclusões de $\mathrm{CO}_{2}$ a partir de um fluido aquo-carbônico e sugerem que o escape da fração aquosa de inclusões aquo-carbônicas (através de microfissuras na cavidade da inclusão) e a deformação dúctil (migração dos limites de grãos de quartzo) podem conduzir a individualização do $\mathrm{CO}_{2} \mathrm{e} \mathrm{H}_{2} \mathrm{O}$. Isso tem sido interpretado como consequiência da grande diferença nas propriedades físico-químicas do $\mathrm{CO}_{2}$ e $\mathrm{H}_{2} \mathrm{O}$ líquidos, conforme sugerido pelos estudos experimentais (e.g. Watson \& Brenan 1987). Considerando um sistema imiscível contendo $\mathrm{H}_{2} \mathrm{O}+\mathrm{CO}_{2}$, a estrutura polar das moléculas do $\mathrm{H}_{2} \mathrm{O}$, comparativamente à não-polar do $\mathrm{CO}_{2}$, favorece sua migração. Isšo tem sido documentado em amostras naturais por Johnson \& Hollister (1995), os quais sugerem que durante o movimento de crescimento do grão de quartzo, $\mathrm{o} \mathrm{CO}_{2}$, com menor taxa de migração, ficaria retido como inclusões, enquanto o $\mathrm{H}_{2} \mathrm{O}$ migraria junto aos limites do grão.

No caso das amostras da área do DASF, as inclusões aquo-

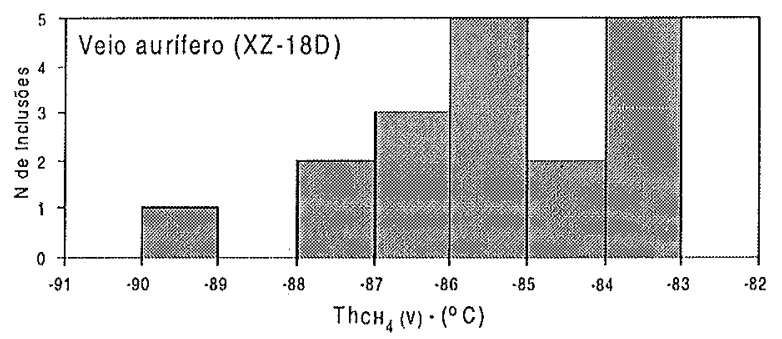

Figura 9 - Histograma de frequiência de temperaturas de homogeneização total, para o estado vapor; de inclusões ricas em $\mathrm{CH}_{4}\left(T h_{\mathrm{CH}}(\mathrm{V})\right.$ ). carbônicas com baixa salinidade $(\sim 3$ a $5 \%$ em peso de $\mathrm{NaCl})$ presentes na amostra do veio estéril tipo III, afetado por baixa deformação, podem ser um registro dos fluidos mais antigos. $O$ volume da fração aquosa destas inclusões é muito variável e deve ser reflexo da perda diferenciada do $\mathrm{H}_{2} \mathrm{O}$. Assim, sugere-se que reativações das microfraturas cicatrizadas que alojavam inclusões aquo-carbônicas proporcionaram o escape do $\mathrm{H}_{2} \mathrm{O}$, preservando total ou parcialmente a fração carbônica. Investigações inéditas na área do DASF vêm corroborando esta proposição (Luiz-Silva em prep.) e confirmam a desidratação de populações inteiras de inclusões originalmente aquocarbônicas, tanto em agrupamentos primários, quanto secundários e pseudo-secundários. Como a densidade de algumas inclusões carbônicas é compatível com as condições do pico metamórfico (e.g. isócoras k e l - Fig. 10), é possível que as modificações nas inclusões originalmente aquo-carbônicas tenham iniciado ainda nas condiçoes do pico P-T, podendo ser mantida a densidade original da inclusão (e.g. Hollister 1990).

Os fluidos aquo-carbônicos iniciais foram diluídos ou substituídos por fluidos aquosos, nos quais a salinidade pode estar relacionada à história do metamorfismo hidrotermal da área do DASF. As reações minerais que ocorreram durante este episódio foram resultantes da troca de elementos químicos entre os fluidos circulantes e os micaxistos encaixantes. As reações iniciais promoveram a formação da zona da cordierita-andaluzita a expensas da zona da granada e envolveram como reagentes a biotita e o plagioclásio (Luiz-Silva 1995). Com a evolução do metamorfismo, que foi marcada pelo aumento da taxa de fluxo de fluido no ambiente, os reagentes e produtos foram envolvidos em novas reações que promoveram a formação da zona da silimanitamuscovita. Cálculos de balanço de massa na área do DASF mostram que a formação das zonas da cordierita-andaluzita e silimanitamuscovita foi acompanhada do transporte expressivo de elementos como Na, K, Li e Ca (menos significativo no caso do Mg e Fe; LuizSilva et al. 2000). Como a zona da silimanita-muscovita marca o ápice/ final do evento metamórfico-hidrotermal, a presença de cátions livres nos fluidos circulantes, sem reaproveitamento pelas reaçð̋es metamórficas, deve ter favorecido a formação de sais mais complexos. Portanto, a complexidade química presente nas inclusöes aquosas dos veios auríferos (zona da silimanita-muscovita) em relação aos estéreis

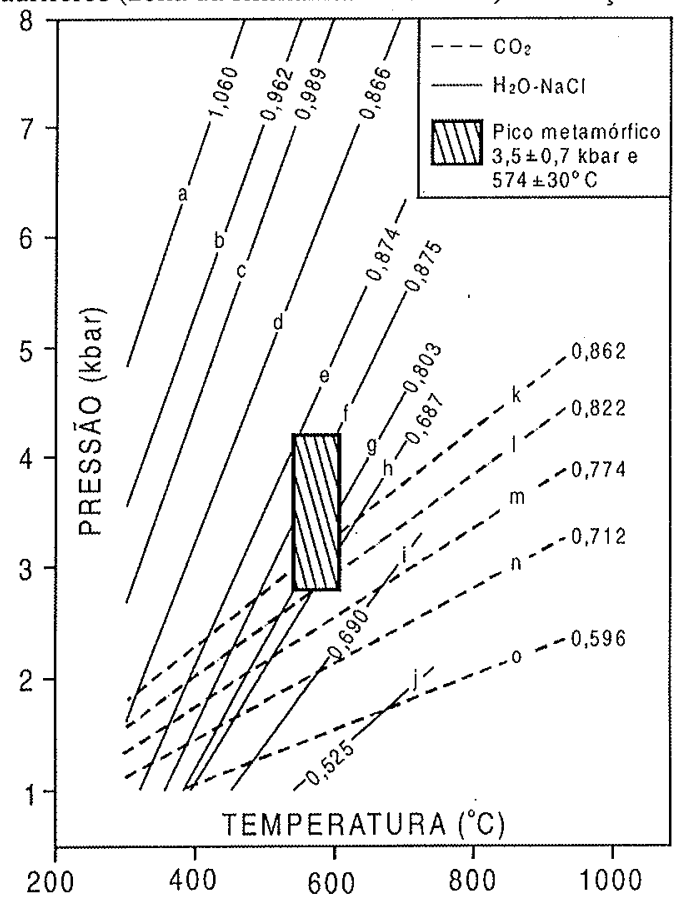

Figura 10 - Isócoras (com valores de densidade em $\mathrm{g} / \mathrm{cm}^{3}$ ) representativas de inclusões de $\mathrm{H}_{2} \mathrm{O}-\mathrm{NaCl}(a-j)$ e $\mathrm{CO}_{2}(k-o)$ da área do depósito aurífero São Francisco (veios auriferos e estéreis). Nota-se que algumas isócoras de ambas as inclusões $(e-h, k, l)$ cruzam a região do pico metamórfico (definido por Luiz-Silva 1995), sugerindo que estas inclusóes foram formadas elou reequilibradas (densidade) nestas condiçós. As isócoras foram calculadas com base nas equaçes de estado de Brown \& Lamb (1989), por meio do programa FLINCOR I.4 (Brown 1989). As inclusĩes utilizadas nos cálculos foram as de $\mathrm{H}_{2} \mathrm{O}-\mathrm{NaCl}$ com $\mathrm{Tf}_{\text {gelo }}$ no intervalo de $-8^{\circ}$ a $\mathrm{O}^{\circ} \mathrm{C}$ e $\mathrm{Th}_{\mathrm{H} 2 \mathrm{O}-\mathrm{L}}$ de $70^{\circ}$ a $400^{\circ} \mathrm{C}$; e de $\mathrm{CO}_{2} \mathrm{com} \mathrm{Tf}_{\mathrm{CO} 2}$ de $10^{\circ}$ a $30^{\circ} \mathrm{C}$. 
(zona da cordierita-andaluzita) deve refletir a história metamórficohidrotermal.

É provável que o ouro do DASF, especialmente aquele relacionado à mineralização primária, tenha sido transportado especialmente pelos fluidos mais antigos, ou seja, aquo-carbônicos com baixa salinidade ( 3 a $5 \%$ em peso de $\mathrm{NaCl}$ ), o que tem sido corroborado por estudos adicionais de inclusões fluidas (Luiz-Silva em prep.). Com relação ao transporte do ouro, há um consenso na literatura de que o $\mathrm{Au}(\mathrm{HS})^{\circ}$, $\mathrm{Au}(\mathrm{HS})_{2}$ - e $\mathrm{AuCl}_{2}$ - são os mais importantes complexos mobilizadores do ouro sob condições hidrotermais (cf. Mikucki 1998). O Au(HS) ${ }^{\circ}$ deve ser dominante $\mathrm{em}$ condições abaixo de $300^{\circ} \mathrm{C}$, enquanto o $\mathrm{Au}(\mathrm{HS})_{2}$ - e $\mathrm{AuCl}_{2}$-, acima deste patamar de temperatura. De acordo com Mikucki (1998), nos fluidos com temperatura inferior a $550^{\circ} \mathrm{C} \mathrm{o}$ $\mathrm{AuCl}_{2}$ - deve substituir eventualmente o $\mathrm{Au}(\mathrm{HS})_{2}-$, mas acima de $550^{\circ}$ $\mathrm{Co} \mathrm{AuCl}{ }_{2}$ - deve ser o complexo dominante no transporte do ouro, até mesmo em um fluido mineralizante com baixa salinidade. Desta forma, os complexos clorados e de enxofre podem ter tido um importante papel no transporte do ouro do DASF, com destaque para o primeiro, devido à elevada temperatura de formação deste depósito.

A remobilização do ouro ( \pm sulfetos) da mineralização primária e sua deposição em fraturas (mineralização secundária) constitui um episódio evidente no DASF. Apesar de não ter sido identificada uma relação direta entre a formação da mineralização tardia (secundária) e o tipo de fluidos envolvidos (e.g. uma microfratura alojando ouro e inclusões fluidas), admite-se que os fluidos aquosos mais salinos (composição química complexa) podem ter sido importantes na remobilização do ouro primário, considerando que os estudos de LuizSilva (em prep.) confirmam que estas soluções circularam durante $\mathrm{C}$ após o regime de fluidos aquo-carbônicos. A remobilização secundária de ouro primário por soluções hipersalinas tem sido documentada por Guha \& Kanwar (1987). O transporte do ouro secundário por soluções aquosas salinas, em oposição ao transporte por soluções aquocarbônicas com baixa salinidade (ouro primário), é admitido por McCuaig \& Kerrich (1998), os quais sugerem que episódios finais de mineralizações podem apresentar características bem diferentes dos iniciais.

Para a concentração do ouro nos veios a partir de fluidos hidrotermais é necessário induzir mudanças na química dos fluidos, capazes de desestabilizar os complexos-Au e remover o ouro da solução. Estas mudanças ocorrem sobretudo com relação ao estado de oxidação ou redução do fluido, incremento no $\mathrm{pH}$ do fluido (especialmente para complexos $\mathrm{Au}-\mathrm{Cl}$ ) ou diminuição da concentração de $\mathrm{S}$ no fluido (especialmente para complexos Au-S). São vários os fatores que provocam a desestabilização dos complexos-Au (cf. Romberger 1990, McCuaig \& Kerrich 1998) e no caso da mineralização primária do DASF devem ter sido importantes: (1) mistura de fluidos; (2) interação fluido-rocha; e (3) imiscibilidade de fases. Embora estes fatores estejam sendo investigados com mais detalhe, a mistura dos fluidos aquocarbônicos de baixa salinidade com aquosos de salinidade complexa (geralmente com elevada concentração de solutos) e a sulfetação (e.g. consumo do $\mathrm{Fe}$ dos micaxistos encaixantes) apontam como mecanismos potenciais para a desestabilização dos complexos-Au. Evidências da mistura de fluidos estão sendo documentadas por Luiz-Silva (em prep.). No tocante ao fator 3 , a imiscibilidade de fases deve ocorrer dentro dos condutos de fluidos formadores dos veios de quartzo, em resposta à queda súbita da pressão de fluidos (Sibson et al. 1988) - no caso do DASF, a abertura das fraturas de cisalhamento que alojam os veios. Esta queda da pressão provoca a desestabilização/precipitação da sílica solubilizada $\left(\mathrm{H}_{4} \mathrm{SiO}_{4}\right)$ e, conseqüentemente, dos complexos de ouro transportados pelos fluidos. Este mecanismo tem sido admitido como de grande importância na formação de corpos de minério (McCuaig \& Kerrich 1998) e, no DASF em particular, pode explicar a ocorrência de ouro livre dentro dos veios de quartzo.

CONCLUSÕES Na área estudada, a participação de uma fase fluida foi fundamental no decurso do metamorfismo e da mineralização aurífera. Algumas das características dos fluidos que circularam no ambiente metamórfico-hidrotermal podem ser extraídas do presente estudo.

1. As inclusões fluidas analisadas estão hospedadas especialmente em microfraturas cicatrizadas de baixo-médio e médio-alto ângulos, com relação à superfície $\mathrm{XZ}$ do elipsóide de deformação finita.

2. Quatro tipos de inclusões fluidas foram identificados, por ordem decrescente de abundância: tipo $1-\mathrm{CO}_{2}$, podendo conter pequena quantidade de $\mathrm{CH}_{4}$ e $\mathrm{N}_{2}$; tipo $2-\mathrm{H}_{2} \mathrm{O}$, podendo conter uma mistura complexa de solutos; tipo 3 - ricas em $\mathrm{CH}_{4}$; e tipo 4 - aquocarbônicas com baixa salinidade. As inclusões tipos 1, 3 e 4 são texturalmente as mais antigas e relacionam-se às microfraturas de baixo-médio ângulo. As inclusões tipo 2, texturalmente as mais jovens, estão alojadas particularmente nas microfraturas de médioalto ângulo.

3. Os veios de quartzo auríferos (veios de cisalhamento) apresentam inclusões fluidas tipos 1, 2 e 3 ; no veio estéril tipo I (veio de cisalhamento) ocorrem inclusões tipos 1 e 2 , e no veio estéril tipo III (veio extensional) ocorrem os tipos $1,2 \mathrm{e} 4$.

4. Um aspecto particular entre os veios auríferos e estéreis é a presença, nos primeiros, de inclusões aquosas com complexa composição $\left(\mathrm{H}_{2} \mathrm{O}-\mathrm{CaCl}_{2} \cdot \mathrm{NaCl} \pm \mathrm{KCl} \pm \mathrm{LiCl} \pm \mathrm{MgCl}_{2} \pm \mathrm{FeCl}_{2}\right)$. Os veios estéreis apresentam inclusões aquosas com composição predominantemente mais simples $\left(\mathrm{H}_{2} \mathrm{O}-\mathrm{NaCl} \pm \mathrm{KCl}\right)$. A presença do $\mathrm{CH}_{4}$, como inclusões ou diluído nas inclusões carbônicas, também é uma característica dos veios auríferos.

5. Algumas inclusões de $\mathrm{CO}_{2}$ e $\mathrm{H}_{2} \mathrm{O}-\mathrm{NaCl}$ dos veios estudados possuem densidades compatíveis com o campo P-T do pico metamórfico $\left(3,5 \pm 0,7 \mathrm{kbar}\right.$ e $\left.574^{\circ} \pm 30^{\circ} \mathrm{C}\right)$, sugerindo que a sua formação/ reequilíbrio ocorreu no contexto da fácies anfibolito.

6. Os dados sobre inclusões fluidas, integrados aos estudos estruturais, petrográficos e sobre metamorfismo, sugerem que fluidos aquo-carbônicos e aquosos circularam durante o pico do metamorfismo. Os fluidos mais antigos devem ter sido aquocarbônicos com baixa salinidade ( 3 a $5 \%$ em peso de $\mathrm{NaCl})$ e foram substituídos/diluídos por fluidos aquosos, podendo conter complexa salinidade.

7. As inclusões dos fluidos aquo-carbônicos, em sua maioria, foram sugestivamente desidratadas, originando inclusões carbônicas. Isso deve ter ocorrido em virtude de reativações das microfraturas cicatrizadas, durante a deformação e exumação da área do depósito. Provavelmente, a saída do $\mathrm{H}_{2} \mathrm{O}$ das inclusões aquo-carbônicas e a retenção do $\mathrm{CO}_{2}$ deve-se às diferenças nas características físicoquímicas destes compostos, que permitem uma maior mobilidade do $\mathrm{H}_{2} \mathrm{O} \mathrm{em}$ relação ao $\mathrm{CO}_{2}$.

8. A complexidade química das inclusões aquosas deve ser um refle xo das reações metamórficas que resultaram da troca de elementos químicos entre os fluidos circulantes e os micaxistos encaixantes. Esta complexidade é maior no caso dos veios auríferos, cuja zona da silimanita-muscovita (hospedeira da mineralização) marca o ápice/final do metamorfismo hidrotermal. Assim, a presença de cátions na fase fluida sem reaproveitamento pelo sistema, deve ter favorecido a formação de sais mais complexos.

9. Embora estudos adicionais sejam necessários, é sugestivo que fluidos aquo-carbônicos com baixa salinidade $(\sim 3$ a $5 \%$ em peso de $\mathrm{NaCl}$ ) tenham transportado o ouro primário na forma de complexos clorados (possivelmente a forma mais importante) e de enxofre. No tocante à mineralização secundária (ouro \pm sulfetos em fraturas), admite-se que os fluidos aquosos mais salinos (composição química complexa) podem ter sido importantes na remobilização do ouro primário. A mistura de fluidos (aquo-carbônicos com baixa salinidade e aquosos com salinidade complexa), a sulfetação (consumo de $\mathrm{Fe}$ dos micaxistos encaixantes) e a imiscibilidade de fases nos condutos de formação dos veios de quartzo devem ter sido importantes para a deposição do ouro, especialmente o primário.

Agradecimentos Ao Departamento de Geologia/Universidade Federal do Rio Grande do Norte pelo apoio nos trabalhos de campo; ao Laboratório de Inclusões Fluidas (microtermometria e microespectroscopia Raman) do Instituto de Geociências/Universidade Estadual de Campinas, em especial ao Sr. Dailto Silva, pelas análises por microssonda Raman; e aos revisores anônimos da RBG pelas sugestões e críticas. Este estudo é parte da Dissertação de Mestrado de W. LuizSilva que agradece ao Instituto de Geociências e Ciências Exatas/Universidade Estadual Paulista (Rio Claro) pela utilização do Laboratório de Microanálise. Os recursos utilizados neste estudo foram fornecidos pelo Conselho Nacional de Desenvolvimento Científico e Tecnológico - CNPq (processo 132836/93-9) e Fundação de Amparo à Pesquisa do Estado de São Paulo - FAPESP (processo 1997/0780-1). A dois revisores anônimos da RBG pelas sugestões e críticas ao original. 


\section{Referências}

Almeida F.F.M., Hasui Y., Brito Neves B.B., Fuck R.A. 1977. Províncias estruturais brasileiras. In: SBG/ Núcleo Nordeste, Simpósio de Geologia do Nordeste, 8, Campina Grande, Atas, 363-391.

Archanjo C.J. 1993. Fabriques de plutons granitiques et deformation crustale du nord-est du Brésil. Laboratoire de Pétrophysique et Tectonique, Université de Toulouse III Toulouse, Thèse de Doctorat, $168 \mathrm{p}$.

Brown P.E. 1989. Flincor. A microcomputer program for the reduction and investigation of fluid - inclusion data. American Mineralogist, 74: 1390-1393.

Brown P.E. \& Lamb W.M. 1989. P-V-T properties of fluids in the system $\mathrm{CO}_{2}-\mathrm{H}_{2} \mathrm{O}-\mathrm{NaCl}$ : new graphical presentations and implications for tluids inclusions studies. Geoch. (5) 53:847-852.

Craw D. \& Norris R.J. 1993. Grain boundary migration of water and carbon dioxide during uplift of garnet-zone Alpine Schist, New Zealand. Jou: Mefamorphic Geology, 11:371-378

Cunba de Souza L. 1996. Zoneographie metamorphic, chemie des mineraux, petrochimie, geocronologie ${ }^{40} \mathrm{Ar}^{34} \mathrm{Ar}$ et historie P.T-t des micashistes entobant le massif gabbro-granitique d'Acari (Brasiliano), ceinture mobile du Seridó (NE du Brésil). Laboratoire de Géologie et Minéralogie, Université Catholique de Louvain, Louvain, Thèse de Doctorat, $345 \mathrm{p}$.

Cunha de Souza L., Luiz-Silva W., Legrand J.M. 199I. Zoneamento metamórfico provocado pelo Maciço Granítico de Acâri (RN): dados preliminares. In: SBG/ Núcleo Nordeste, Simpósio de Geologia do Nordeste, 14, Recife, Atas, 232-235.

Dantas E.L. Van Schmus W.R. Hackspacher P.C. Brito Neves B.B. 1995. Terrenos arqueanos e paleoproterozóicos do Macico Caldas Brandão na Província Borborema. In: SBG/ Núcleo Nordeste, Simpósio de Geologia do Nordeste, 16, Recife, Atas, 423-427.

Davis D.W., Lowenstein T.K., Spencer R.J. 1990. Melting behavior of fluid inclusions in laboratory-grown halite crystals in the systems $\mathrm{NaCl}-\mathrm{H}_{2} \mathrm{O}, \mathrm{NaCl}-\mathrm{KCl}-\mathrm{H}_{2} \mathrm{O}, \mathrm{NaCl}-$ $\mathrm{MgCl}_{2}-\mathrm{H}_{2} \mathrm{O}$, and NaCl-CaCl$-\mathrm{H}_{2} \mathrm{O}$. Geoch. Cosmoch. Acta, 54:591-601.

Diamond L.W. 1994 . Salinity of multivolatile fluid inclusions determined from clathrate hydrate stability. Geoch. Cosmoch. Acra, 58:19-41.

Etheridge M.A., Cox S.F., Wall F.J., Vernon R.H. 1984. High fluid pressures during regional metamorphism and deformation: implications for mass transport and deformation mechanisms. Jour: Geophys. Res., 89:4344-4358.

Ferran A. 1988. Mina de ouro São Francisco, Currais Novos, Rio Grande do Norte. In: C. Schobbenhaus \& C.E.S. Coelho (coord.). Principais Depósitos Minerais do Brasill,
Metais Básicos nấ-Ferrosos, Ouro e Alunínio. Rio de Janeiro, DNPM, 3:589-595,

França VMO \& Legrand JM 1989. Transferência térmica por convecção na crosta e suas implicações sobre a geometria das isógradas metamórficas: caso dos gnaisses e micaxistos da região do Seridó (RN). In: SBG, Simpósio Nacional de Estudos Tectônicos, 2, Fortaleza, Atas, $251-254$.

Fuzikawa K. 1985. Inclusões fluidas: métodos usuais de estudo e aplicações. In: Contribuif́nes à Geologia e à Petrologia. Boletim Especial da SBG/ Núcleo de Minas Gerais. Belo Horizonte, SBG. p. 29-44

Groves D.I. I990. Stuctural setting and control of gold deposits. In: F. Robert, P.A. Sheahan, S.B. Green (ed.) Greenstone gold and crustal evolution. NUMA Conference Volume, Val d'Or, 1990, Geological Association of Canada, 79-85.

Guba J. \& Kanwar R. 1987. Vug brines - fluid inclusions: A key to understanding of secondary gold enrichment processes and the evolution of deep brines in the Canadian Shield. In P. Fritz, S.K. Frape (ed.) Saline water and gases in the crystalline rocks. Montreal, Geological Association of Canada, 95-101. (Special Paper, n. 33).

Hackspacher PC, Dantas E.L., Brito Neves B.B., Legrand J.M. 1997. Northwestern overthrusting and related lateral escape during the Brasiliano Orogeny, north of the Patos Lineament, Borborema Province, NE-Brazil. Internat. Geol. Review, 39:609. 620

Hodgson, C.J. 1989. The structure of shear-related, vein-type gold deposits: a reviews. Ore Geology Reviews, 4: 231-273

Hollister L.S. 1990 . Enrichment of $\mathrm{CO}_{2}$ in fluid inclusions in quartz by removal of $\mathrm{H}_{2} \mathrm{O}$ during crystal-plastic deformation. Jour Struct. Geology, 12:895-901.

Jardim de Să E.F. 1984. Geologia da Região do Seridó: reavaliação de dados. In: SBG/ Núcleo Nordeste, Simpósio de Geologia do Nordeste, 11, Natal, Atas, 278-296.

Jardim de Sá E.F. 1994. A Faixa Seridó (Provincia Borborema NE do Brasil) e o seu significado geodinâmico na Cadeia Brasiliana/Pan-Africana. Instituto de Geociências, Universidade de Brasília, Brasília, Tese de Doutoramento, 803 p.

Jardim de Sá E.F. \& Salim J. 1980. Reavaliação dos conceitos estratigráficos na regiăo do Seridó (RN-PB). Mineração e Metalurgia, 80:16-28.

Johnson E.L. \& Hollister L.S. 1995. Syndeformational fluid tapping in quartz: determining the pressure-temperature conditions of deformation from fluid inclusions and the formation of pure $\mathrm{CO}$, fluid inclusions during grain-boundary migration. Jow: Metamor: Geology, 13:239-249.

Kerkhof A.M. van den \& Olsen S.N. 1990. A natural example of superdense $\mathrm{CO}_{2}$ inclusions: microthermometry and Raman analysis. Geoch. Cosmoch. Acta, 54:895-901

Kerkhof A.M. van den, 1988. The system $\mathrm{CO}_{2}-\mathrm{CH}_{4}-\mathrm{N}_{2}$ in fluid inclusions: theoretical modeling and geological applications. Vrije Universiteit te Amsterdam, Amsterdam, Doctor of Philosophy Thesis, $206 \mathrm{p}$.

Kerrich R. \& Cassidy K.F. 1994. Temporal relationships of lode gold mineralization to accretion, magmatism, metamorphism and deformation - Archean to present: review. Ore Gerlogy Reviews, 9:263-310

Legrand J.M., Almeida H.L., Cunha de Souza L. 1992. Metamorfismo aloquímico: caso do canais térmicos dos micaxistos Seridó/RN. In: SBG, Congresso Brasileiro de Geologia, 37, São Paulo, Restmos: Expandidess, 1:429-430.

Legrand J.M. \& França V.M.Q. 1989. Implicação geotectônica do metamorfismo brasiliano na Faixa Seridó (RN) e suas relaçōes com os granitóides intrusivos. In: SBG, Simpósio Nacional de Estudos Tectônicos, 2, Fortaleza, Atas, 233-236.

Legrand J.M., Luiz-Silva W., Cunha de Souza L. 1995. Os micaxistos da Formação Seridó: Um único evento metamórfico progressivo do Ciclo Brasiliano. In: SBG/ Núcleo Nordeste, Simpósio de Geologia do Nordeste, 16, Recife, Atas, 361-365.

Lima E.A.M. et al. 1980. Projeto Scheelita do Seridó. Relatorio Final e Mapas. Recife DNPM/CPRM, 1284
Luiz-Silva W. 1995. Estudos da interaçāo fluido-rocha na área do depósito aurifero São Francisco, Currais Novos (RN): aspectos estruturais e metamórficos. Instituto de Geociências e Ciências Exatas, Universidade Estadual Paulista, Rio Claro, Dissertação de Mestrado, $183 \mathrm{p}$.

Luiz-Silva W. em prep. Mineralizações auríferas em veios de quartzo na Faixa Seridó, NE do Brasil: exemplos de depósitos de ouro de fácies anfibolito em faixa móvel proferozóica. Instituto de Geociências e Ciências Exatas, Universidade Estadual Paulista, Rio Claro, Tese de Doutoramento, $2 \mathrm{v}$.

Luiz-Silva W., Hackspacher P.C., Legrand J.M. 1997. Arcabouço estrutural da área do depósito aurífero São Francisco (RN) e a geodinâmica neoproterozóica na Faixa de pósito aurífero São Francisco (RN) e a geodinâmica neoproterozóica

Luiz-Silva W. \& Legrand J.M. 1996. Termobarometria no depósito aurifero São Francisco (RN): evolução metamórfica e caracterização P-T da mineralização. In: SBG, Congresso Brasileiro de Geologia, 39, Salvador, Anais, 3:346-349.

Luiz-Silva W. Legrand J.M., Cunha de Souza L. 1993. Evidências microte ência hidrotermal na cristalização de tipomórficos nos Micaxistos Seridó (RN). In: SBG/ Núcleo Nordeste, Simpósio de Geologia do Nordeste, 15, Natal, Akas, 120 123.

Luiz-Silva W., Legrand J.M., Cunha de Souza L. 1994. O metamorfismo hidroterma brasiliano na Formação Seridó e sua relação com a estruturaçāo regional. In: SBG Congresso Brasileiro de Geologia, 38, Camboriú, Boletim de Resumos Expandidos, 3: $84-85$.

Luiz-Silva W. Xavier R.P., Legrand J.M. 2000. Mass transfer during the metamorphism of the Seridó schist, northeastern Brazil. In: International Geological Congress, 3I, Rio de Janeiro. (no prelo)

McCuaig T.C. \& Kerrich R. 1998. P-T-t-deformation-fluid characteristics of lode gold deposits: evidence from alteration systematics. Ore Geol. Rev., 12:381-453.

Mikucki E.J. 1998. Hydrothermal transport and depositional processes in Archean lode-gold systems: a review. Ore Geol. Rev, 13:307-321

Molnar F., Watkinson D.H., Everest J.O. 1999. Fluid-inclusion characteristics of hydrothermal $\mathrm{Cu}-\mathrm{Ni}$-PGE veins in granitic and metavolcanic rocks at the contact of the Little Stobie deposit, Sudbury, Canada. Chemical Geology, 154:279-301

Olsen S.N. \& Ferry J.M. 1995. A comparative fluid inclusion study of the Waterville and Sagerville (Vassalboro) formations, south-central Maine. Contr: Mineral Petrol, 118:396-413.

Robert F. \& Kelly W.C. 1987. Ore-forming fluids in Archaean gold-bearing quartz veins at the Sigma Mine, Abitibi greenstone belt, Quebec, Canada. Econ. Geol., 82:1464. 1482 .

Robert F. Phillips G.N., Kesler S.E. 1990. Greenstone gold and crustal evolution: scope and results of the conference. In: F. Robert, P.A. Sheahan, S.B. Green (ed.) Greenstone gold and crustal evolution. NUMA Conference Volume, Val d'Or, 1990, Geological Association of Canada, 2-7.

Roedder E. 1984. Fluid inclusions. Michigan, Mineralogical Society of America, 646 p. (Reviews in Mineralogy Series, 12)

Romberger S.B. 1990. Transport and deposition of gold in hydrothermal systems. In: F. Robert, P.A. Sheahan, S.B. Green (ed.) Greenstone gold and crustal evolution. NUMA Conference Volume, Val d'Or, 1990, Geological Association of Canada, 6166.

Shepherd T.J., Bottrell S.H., Miller M.F. 1991. Fluid Inclusion volatiles as an exploration guide to black shale-hosted gold deposits, Dolgellau gold shale belt, North Wales, U.K. Jotrnal of Geochemical Exploration, 42:5-24

Sherlock L.R., Jowett E.C., Smith B.D., Irish D.E. 1993. Distinguishing barren and auriferous veins in the Sigma Mine, Val-d'Or, Quebec. Can. Jour. Earth Sci., 30:413-419.

Sibson R.H. 1990. Fault structure and mechanics in relation to greenstone gold deposits. In: F. Robert, P.A. Sheahan, S.B. Green (ed.) Greenstone gold and crustal evolution. NUMA Conference Volume, Val d'Or, 1990, Geological Association of Canada, 5460 .

Sibson S.H., Robert F., Poulsen H. 1988. High angle faults, fluid pressure cycling and mesothermal gold-quartz deposits. Geology, 16:551-555

Sibson R.H. \& Scott J. 1998. Stress/fault controls on the containment and release of overpressured fluids: examples from gold-quartz vein systems in Juneau, Alaska, Vitoria, Australia and Otago, New Zealand. Ore Geol. Rev., 13:293-306.

Sisson V.B. \& Hollister L.S. 1990. A fluid-inclusions study of metamorphosed pelitic and carbonate rocks, south-central Maine. Amer: Mineral., 75:59-70.

Van Schmus W.R., Dantas E.L., Fetter A.H., Brito Neves B.B., Hackspacher P.C., Babinski M. 1996. Neoproterozoic age for Seridó Group, NE Borborema Province, Brazil. In: SBG, Congresso Brasileiro de Geologia, 39, Salvador, Anais, 6:152-155.

Watson E.B. \& Brenan J.M. 1987. Fluids in the lithosphere, 1. Experimentally-determined wetting characteristics of $\mathrm{CO}_{2}-\mathrm{H}_{2} \mathrm{O}$ fhids and their implications for fluid transport, host-rock physical properties, and fluid inclusion formation. Earth Planet. Sci. Letter, 85:497-515.

Xavier R.P. 1987. Estudos de inclusões fluidas na Mina de Ouro Fazenda Brasileiro, greenstone belt do Rio Itapicuri, Bahia. São Paulo. Instituto de Geociências, Universidade de São Paulo, São Paulo, Dissertação de Mestrado, 142 p.

Xavier R.P. 1994 . Monophase carbonic inclusions in precambrian mesothermal gold deposits: results of phase separation of fluid-rock interaction? In: Pan-American Current Research on Fluid Inclusions, 5. Cucmavaca, Abstracts, I 23-124.

Xavier R.P. \& Foster R.P. 1999. Fluid evolution and chemical controls in the Fazenda Maria Preta (FMP) gold deposit, Rio Itapicuru Greenstone Belt, Bahia, Brazil. Chentical Geol., 154:133-154.

Xavier R.P. Foster R. P. Fallick A.E. Alderton D.H, 1994. Potential fluid reservoirs for mesothermal gold deposits in Rio Itapicuru greenstone belt, Bahia, Brazil. Comunicaciones, 45:13-22

Manuscrito A.932

Recebido em 30 de julho de 1997

Revisào dos autores em 15 de maio de 2000 Revisão aceita em 25 de maio de 2000 